\title{
صعوبات استخدام برنامج "التيمز" من وجهات \\ نظر مديري المدارس بمديرتي قلقيلية و جنوب نابلس وسبل مواجهتها
}

عبير خالد حسين قشوع'، سها أسعد إبراهيم جلاد²، شادي خالد حسين قشوع³ 2،1 جامعة النجاح الوطنية، فلسطين

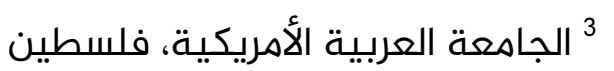

1 abeer.qashoo7@gmail.com, ${ }^{2}$ Sohajallad8@gmail.com, ${ }^{3}$ shadiqashoo@gmail.com

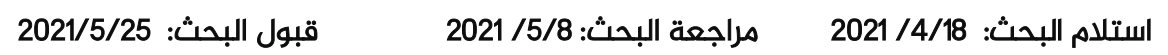


صعوبات استخدام برنامج "التيمز" من وجهات نظر مديري المدارس بمديرتي قلقيلية وجنوب نابلس وسبل مواجهتها

\author{
عبيرخالد حسين قشوع، سها أسعد إبراهيم جلاد²، شادي خالد حسين قشوع33 \\ 2، جامعة النجاح الوطنية، فلسطين \\ الجامعة العبية الأمريكية، فلسطين النجاين
}

${ }_{1}^{1}$ abeer.qashoo7@gmail.com, 2 Sohajallad8@gmail.com, ${ }^{3}$ shadiqashoo@gmail.com

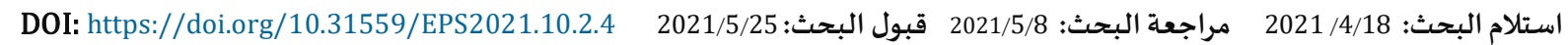

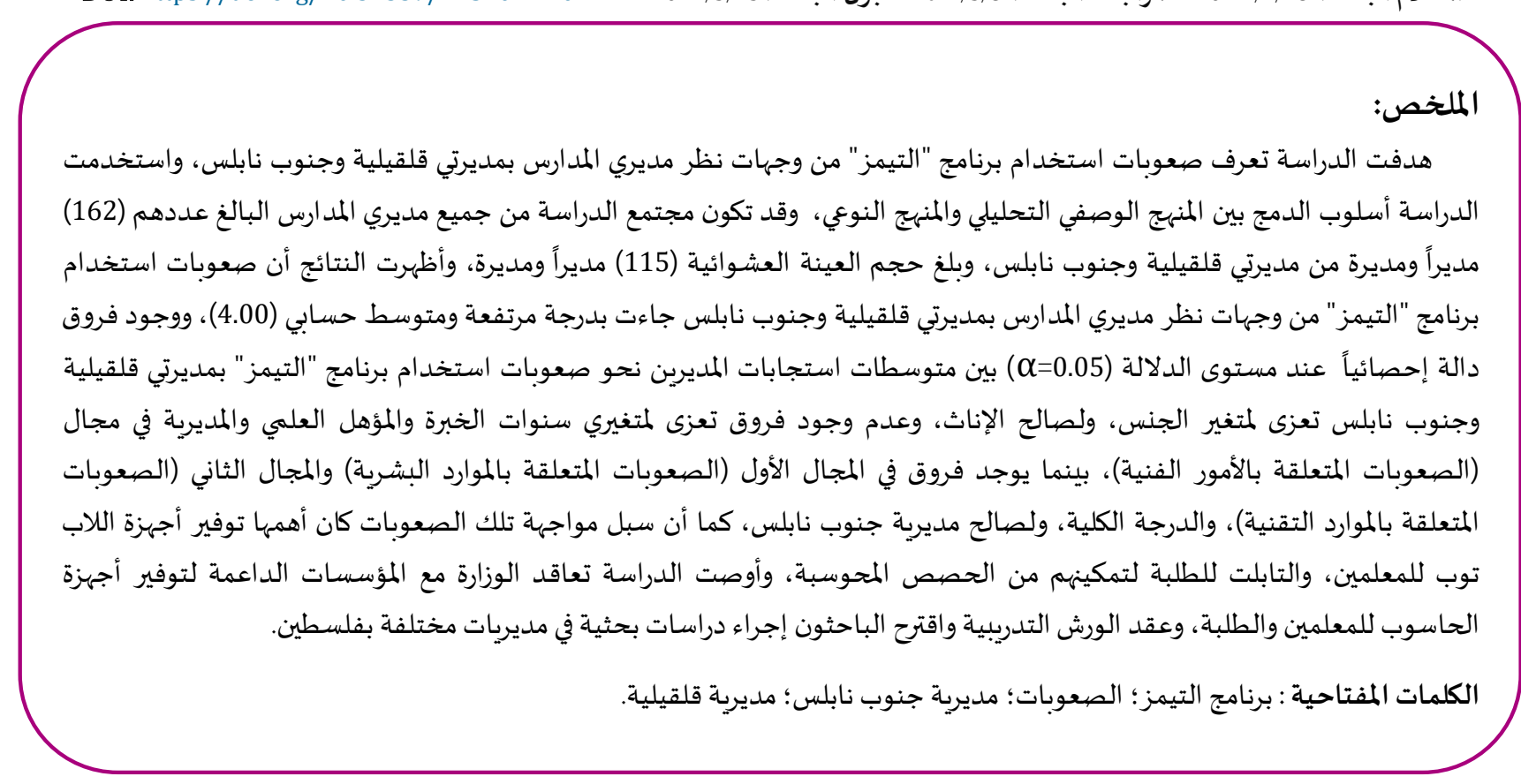

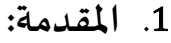

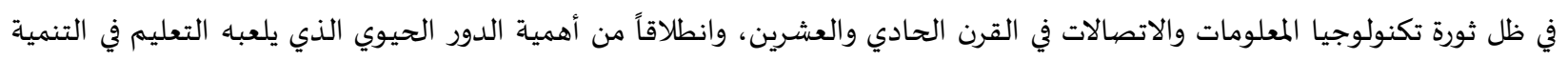

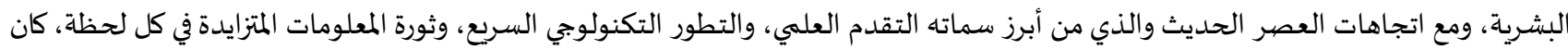

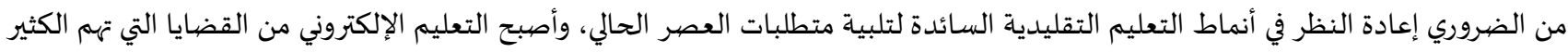

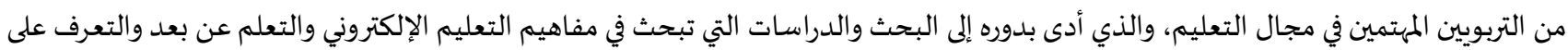

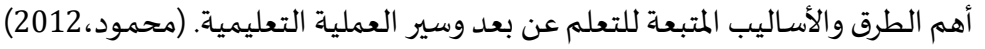

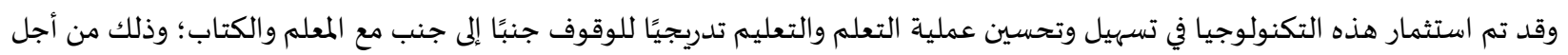

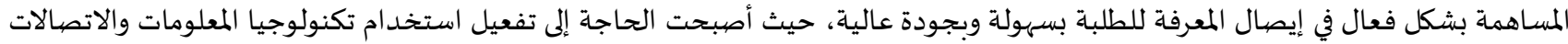

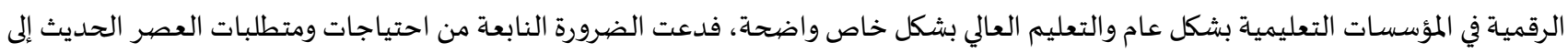


استخدام الأساليب الحديثة لتجاوز الصعوبات والتحديات الناشئة عن التغيرات العالمية، وإلى الإدخال المستمر لأجهزة الكمبيوتر وتطبيقاتها بما في ذلك الإنترنت العالمي والمناهج الإلكترونية في عملية التعلم التربوي. (الحجايا، 2010) ويرى محمود (2012) أنه على الرغم من الإنجازات الكمية التي تحققت في البلاد العبية في التقدم التكنولوجي إلا إن واقع الإنجازات النوعية ما

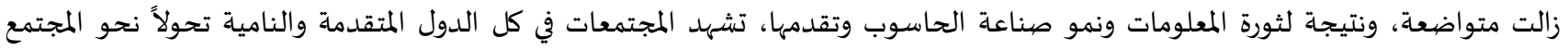

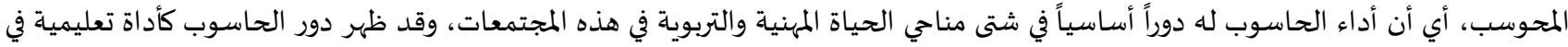

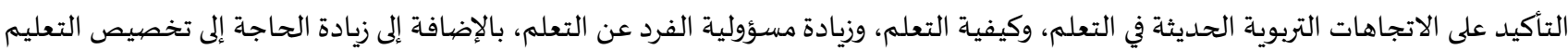

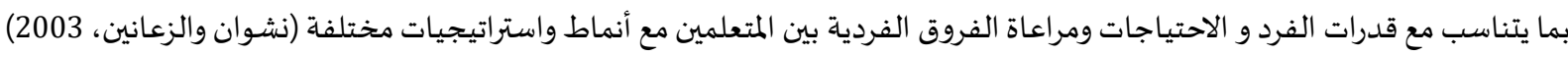

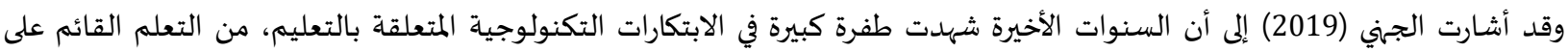
الكمبيوتر، إلى استخدام الإنترنت في العملية التعليمية ومنها إلى التعلم الإلكتروني، ويرى الراضي التهي التهات (2010) التعليم الإلكتروني وسيلة من وسائل التعلم

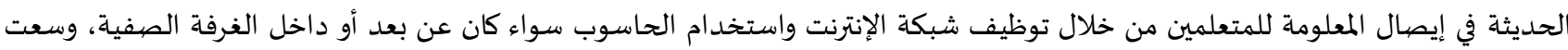

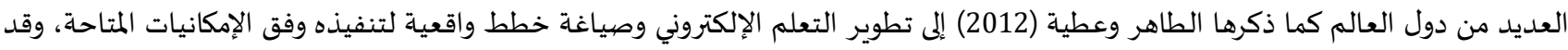
أتت الجهود العبية وراء جهود عالمية وبينت رؤيتها المستقبلية فيما يتعلق بالعملية التعليمية ودور التعلم الإلكتروني، فتم تحديد هذه الرؤية، وعليه

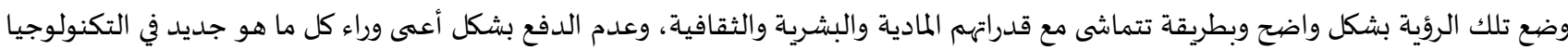
دون مراعاة ظروفها.

وقد عرف سليمان (2008) التعليم الإلكتروني بأنه :نظام يمكّن الطلبة من الدراسة والبحث والتواصل والتفاعل مع أقرانهم ومعلميهم داخل المدرسة وخارجها بأي وقت ممكن، ومن أجل إحداث التعلم، بحيث يشمل هذا النظام على الدورات والدروس التعليمية المعدة لإمكانية الوصهول على بلى

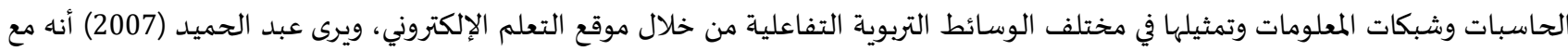

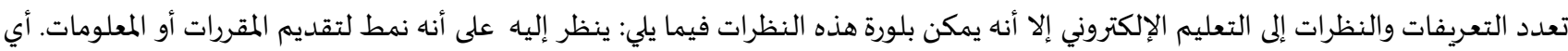

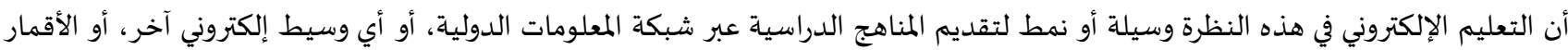

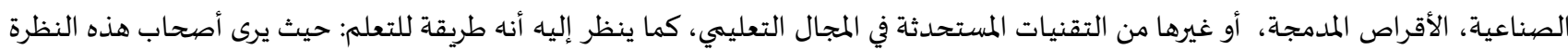
أن التعليم الإلكتروني طريقة للتعليم أو التدريس يستخدم فياه وسائط تكنولوجية متقدمة، كالوسائط المتعدددة، وشبكة المعلومات الدولية، والأقمار الصناعية، حيث يتفاعل كلا الطرفين في العملية التعليمية من خلال هذه الوسائط لتحقيق أهداف تعليمية محددة.

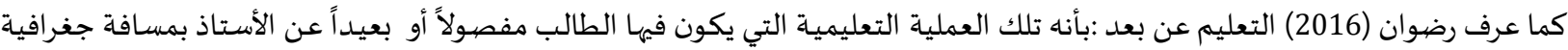
يتم عادة سدها باستخدام وسائل الاتصال الحديثة، فهو نظام تعليهي غير تقليدي يمكن الدارس من التحصيل العلمي والاستفادة من العملية التعليمياة بكافة جوانها دون الانتقال إلى موقع الدراسة ويمكن المحاضرين من إيصال معلومات ومناقشات للمتعلم دون الانتقال إليهم، كما أنها يسمح

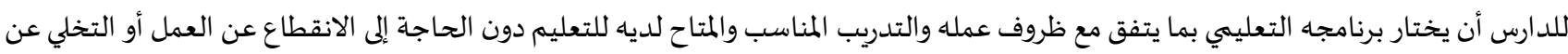
الارتباطات الاجتماعية

ولم يعد التعليم عن بعد كما يرى عميرة وآخرون (2019) مقتصراً على أجهزة الكمبيوتر والأجهزة اللوحية والهواتف الذكية، بل أصبح هناك

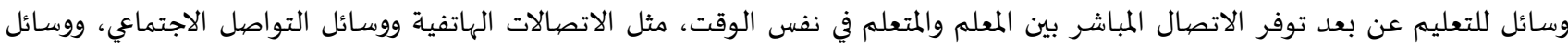

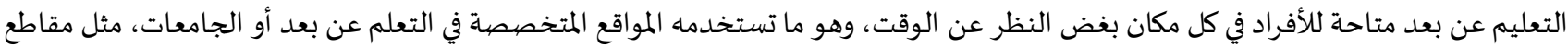

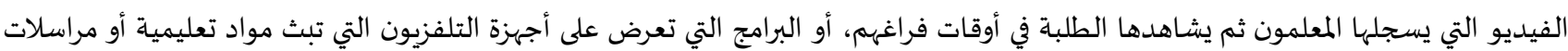
عبر الإنترنت كالشبكات الاجتماعية مثل (Facebook و Twitter و و

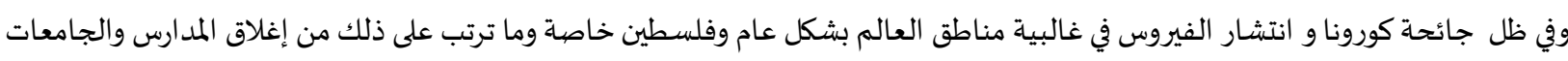
في مختلف أنحاء العالم وانقطاع الطلبة من التوجه إليها خلال العام الدراسي (2019-2020) مما دفع للقائمين على العملية التعليمية في غالبية الدول

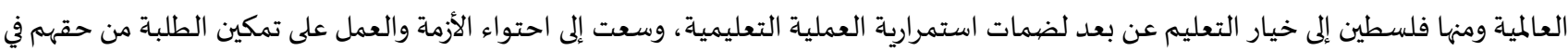
التعليم يتبني استراتيجيات التعليم عن بعد واعتماد المنصات التعليمية المختلفة في الجامعات والمدارس. وقد عرف رضوان (2016) المنصات التعليمية بأهها أرضيات تدريب عن بعد تعتمد على تقنيات WAP ، وتستخدم كميادين يتم من خلالها عرض المات الأعمال وكل ما يتعلق بالتعليم الإلكتروني بما في ذلك الدورات الإلكترونية حيث تحتوي على أنشطة ومن خلالها تتحقق عملية التعلم باستخدام مجموعة من أدوات الاتصال والتواصل، وتمكين المتعلم من الحصول على الدورات والبرامج اللازمة، وتتعد هذه المنصات التعليمية المستعملة في

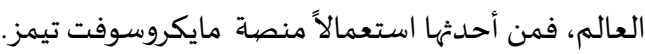
ومن الملاحظ بحثياً قبل ظهور فايروس كورونا (COVID-19)، كان استخدام مختلف منصات التعلم عبر الإنترنت والموارد مكملة بشكل أساسي في

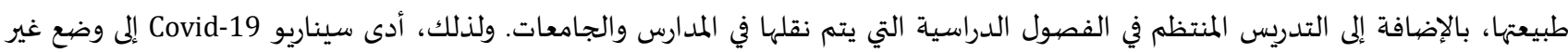


مسبوق، حيث كان هناك تغيير جذري في الطريقة التي تم بها تقديم التعليم ليكون "على الإنترنت فقط" بشكل صارم، واضطر المعلمون إلى إلقاء

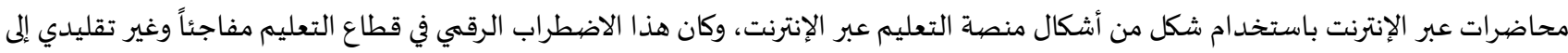

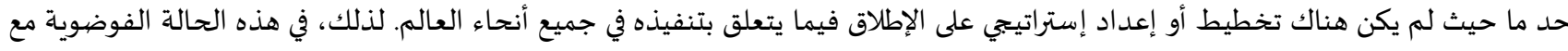

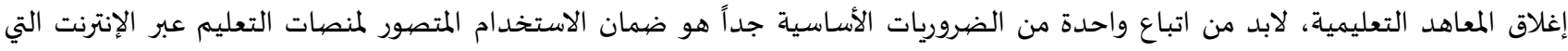

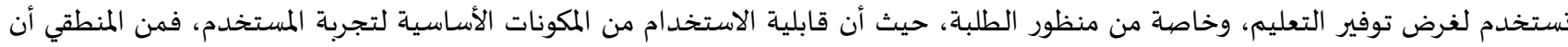

تجربة المستخدم الجيدة تؤدي إلى مستويات أعلى من الارتياح، والتي بدورها يمكن أن تضمن نجاح منصات منات التهات التعليم عبر الإنترنت (مايكروسوفت تيمز).

(Debajyoti.2020)

وقد ذكر سرحان (2020) بأن (Microsoft Teams) أصبح مركزًا للعديد من الموظفين والمتعلمين حول العالم وفقًا للإحصاءات التي تم الإعلان

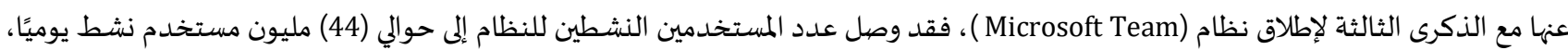

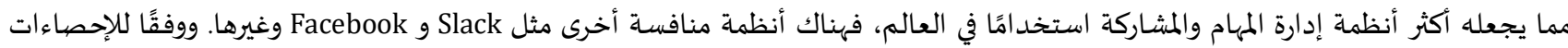

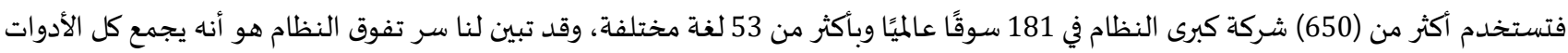

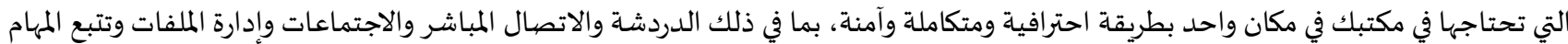

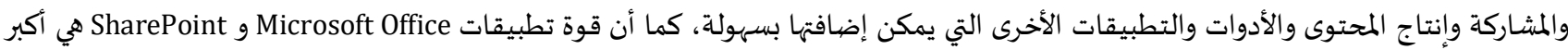
سر وراء قدرة Microsoft على بناء مثل هذا النظام.

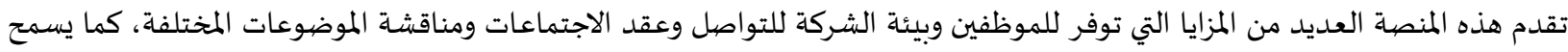

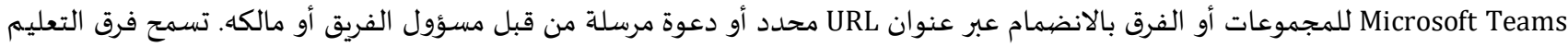
للمعلمين بإعداد فرق محددة للفصول ومجتمعات التعلم المهنية (PLCs) والموظفين والجميع، فضمن Microsoft Teams يمكن للأعضاء إعداد

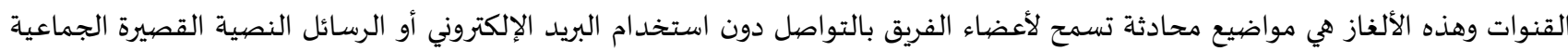

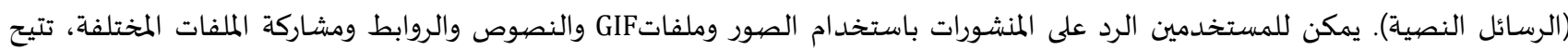

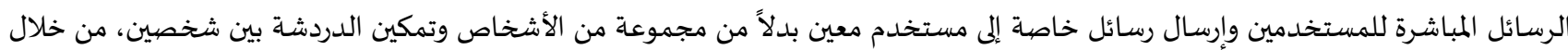

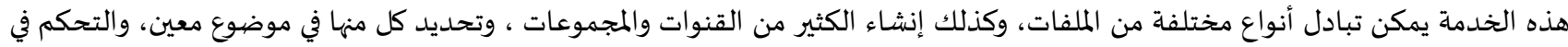

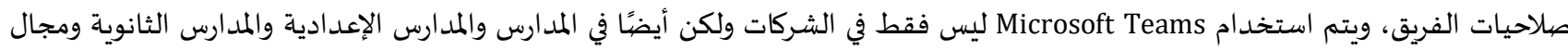
التعليم. (https://www.arrajol.com/content/140571)

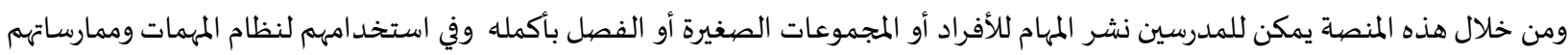

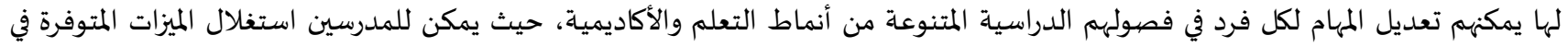

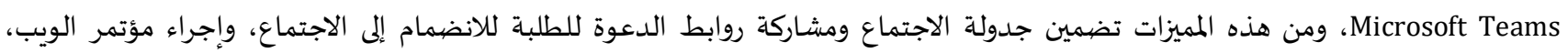

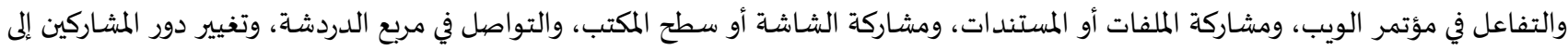
الحضور أو مقدم، وتسجيل مؤتمر الويب، وكذلك تنزيل التسجيل والمواد، وكذلك بيئة التعلم ،فهي من العوامل المهمة التي تساعد الطلبة في تحقيق المكاريق هدف التعلم على النحو الأمثل. ( Allison \& Hudson 2020)

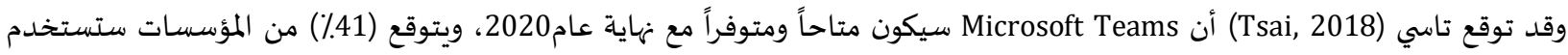
ولى Microsoft Teams الصغيرة والمتوسطة الحجم والشركات، وجاء المشاركون من مجموعاة متنوعة من الصناعات، إلى جانب التصنيع، الرعاية الصحية والمؤسسات غير الصرات

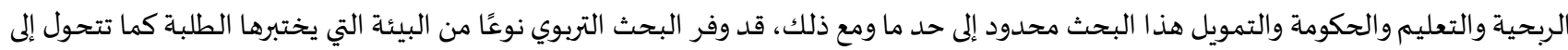
مكان العمل.

1.1. الدراسات السـابقة: - 2.1

وقد تناولت العديد من الدراسـات البحثية موضوع التعليم الإلكتروني، وتحدياته، والتعليم عن بعد واستخد ام المنصيات التعليمية المختلفة: كدراسة روجابي(RojabI,2020) هدفت الدراسة إلى استكشاف تصورات الطلبة للتعلم عبر الإنترنت عبر Microsoft Teams، تكونت عينة

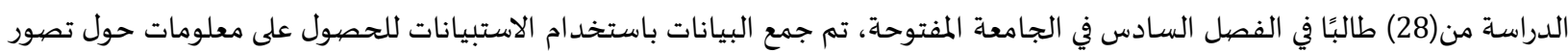
طلبة اللغة الإنجليزية كلغة أجنبية للتعلم عبر الإنترنت عبر Microsoft Teams، وقد تم توزيع الاستبيان على الطلبة من خلال نماذج Google

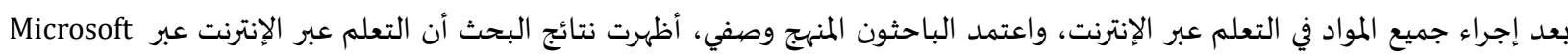


Teams يُصنف على أناه شيء جديد للطلبة، لكن هذا التفاعل وبيئة التعلم حفز الطلبة على المشاركة في التعلم عبر الإنترنت، ونتيجة لذلك يمكنهم بسهولة فهم المواد التعليمياة. كما أجرى كل من ليو ؛ شوفان (Liu, Chenxi; Xu, Fan, 2020) دراسة حللت أربعة أنظمة مؤتمرات فيديو مستخدمة على نطاق واسع: Zoom و Skype و MhatsApp Microsoft Teams، باستخدام التعلم الإلكتروني التجريبي كإطار للتحليل، فحصت هذه الدراسة الخصائص العامة للأنظمة والميزات المتعلقة بالتعلم وسهولة الاستخدام، أجري تقييمًا تحليليًا وتم تحليل ميزات النظام فيما يتعلق بتأثيرها على جودة التجربية

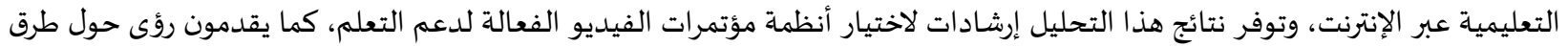
استكشاف مناهج التدريس وطرق التدريس للتعليم عن بعد. وقام ديباجيوتي (Debajyoti, 2020) بدراسـة هدفت إلى تقييم قابلية الاستخدام المتصيور لـ Microsoft Teams كنظام أساسي للتعلم عبر Microsoft Teams الإنترنت خلال COVID-19 باستخدام مقياس قابلية استخدام النظام ونموذج قبول التكنولوجيا في الهند، يتم استخدام

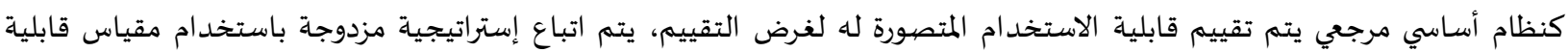

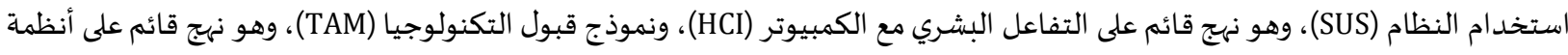

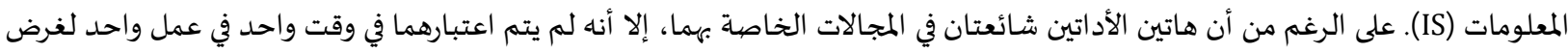

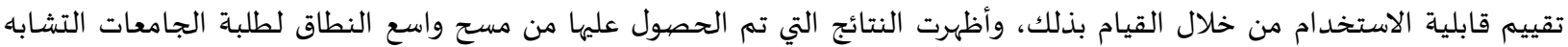

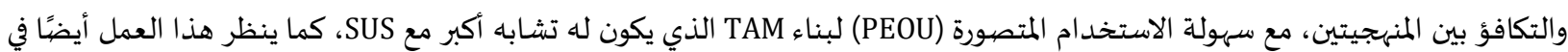

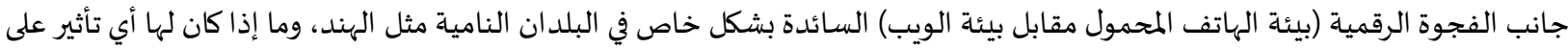

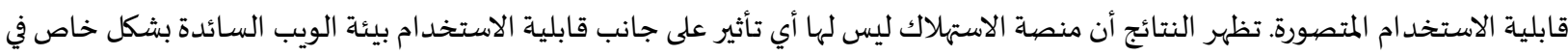

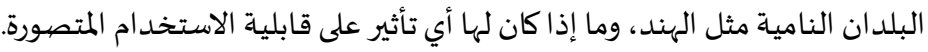
كما قام كل من باسيليا وكفافادزه (Basilaia; Kvavadze, 2020) بدراسة هدفت إلى الوقوف على قدرات الدولة وسكانها لمواصلة عملية التعليم

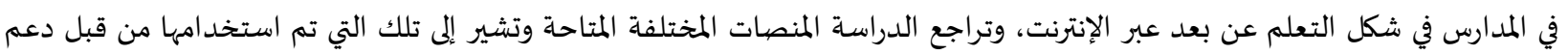
الحكومة، مثل الإنترنت البوابة الإلكترونياة، وفرق Microsoft و TV School للمدارس العامة والبدائل مثل Zoom و Slack و Google Meet

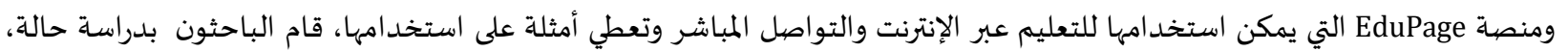
حيث تم تنفيذ منصة Moogle Met للتعليم عبر الإنترنت في مدرسة خاصة تضهم (950) طالبًا، والتي تُظهر إحصاءات الاستخدام التي تم

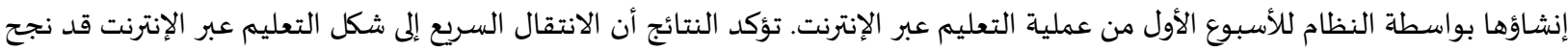

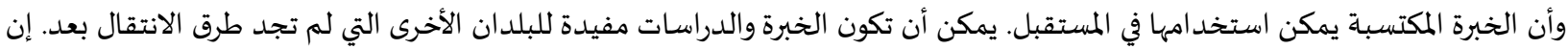

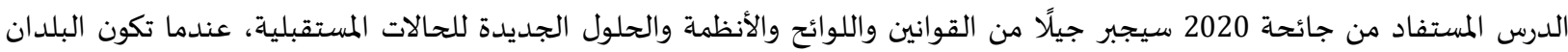
والحكومات والسكان أكثر استعدادًا من اليوم.

وهدفت دراسة مقدادي (2020) إلى الكشف عن تصورات طلبة المرحلة الثانوية في المدارس الحكومية في الأردن استخد ام التعليم عن بعد في ظل أزمة كورونا ومستجدداتها، والتعرف إلى دلالة الفروق في تصورات طلبة المرحلة الثانوية عن استخدام التعليم عن بعد في الأردن وفقاً لمتغير

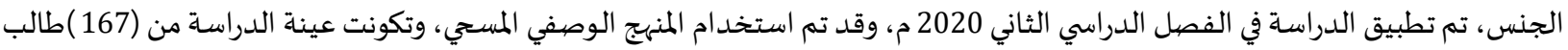
وطالبة، تم اختيارهم بالطريقة العشوائية البسيطة، أظهرت الدراسة نتائج ايجابية لاستخدام التعليم عن بعد في ضوء إسئ جائحة كورونا (كوفيد-

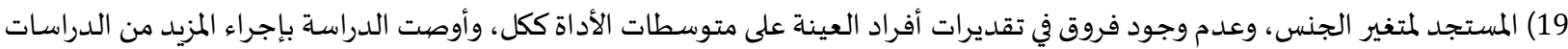

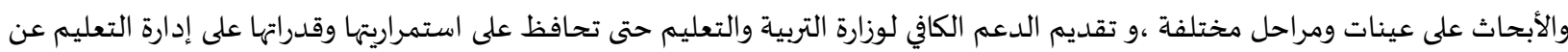
بعد، دعم لمشاريع الوطنية التي تنهي فكرة التعليم عن بعد، وتعزيز التعاون بينها وبين وزارة التعليم الأردنية. وهدفت دراسـة أحمد (2020) الوقوف على أهم تحديات التعليم الرقهي في الوطن العربي من خلال رؤية تأصيلية، في محاولة لمواجهة هذه التحديات من منطلق فكري أقرب للجذور والخلفيات الإسلامية للأمة العربية، استخدم الباحث المنهجين الاستقرائي والاستنباطي لمناسبتهما لطبيعة موضوع الدراسة، وتمثلت أهم نتائج هذه الورقة في صياغة تحديات في المحور الفكري تركز على النظرة للعلوم الحديثة على أنها فتح من

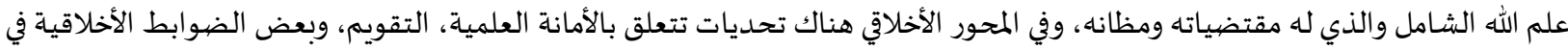

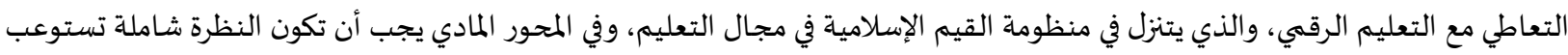
السنن الروحية في الشريعة الإسلامية. ثم يوصي الباحث بمواجهة ومعالجة هذه التحديات باستصحاب الرؤى التأصيلية المستندة إلى وحي الله عز وجل. وأخيراً يقترح الباحث موضيوعات مشابهة ومكملة في بقية القضايا التربوية المعاصرة. 
وهدفت دراسة المصر اتي وضيو (2020) الوقوف على أهم التحديات والصعوبات التي تواجه دمج التعليم الإلكتروني ضمن العملية التعليمية في

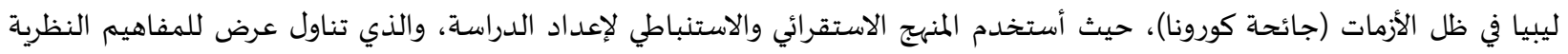

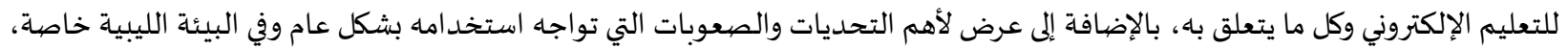

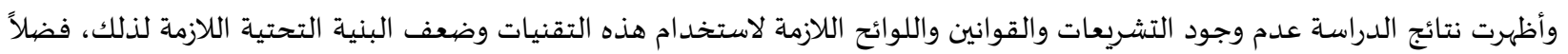

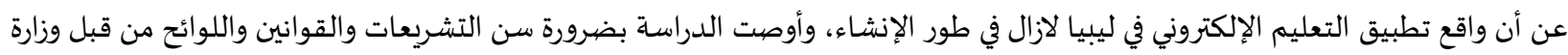

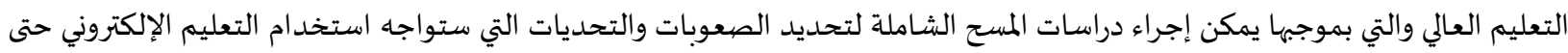

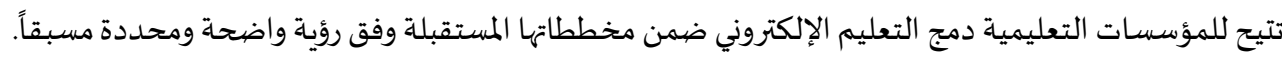
أما دراسة حسن وعمي (2019) فقد هدفت معرفة معوقات تطبيق التعليم الإلكتروني وسبل معالجتها لدى طلبة الدراسات العليا في كلية التربية بجامعة واسط العراق البالغ عددهم (43) طالباً وطالبة، وقد أجرى الباحثان مقابلات نوعية مع الطلبة، وتوصيلت الدورئ الدراسة إلى وجود معوقات

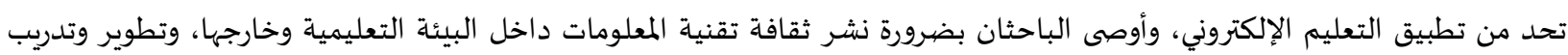
العنصر البشري على استعمال التعليم الإلكتروني، وتوفير البنية التحتية التي تساهم في بناء التعليم الإلكتروني. كما وأجرى الباوي (2019) دراسـة هدفت إلى تقصي أثر استخدام المنصة التعليمية classroom google في تحصيل طلبة قسم الحاسبات لمادة تداتجاهاتهم نحو التعليم الإلكتروني، وقد طبقت الدراسة على مدى عام دراسي كامل بواقع يوم واحد أسبوعياً حيث تم

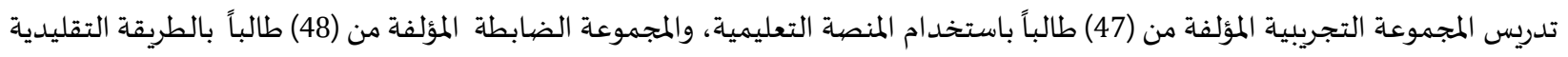
استخدم الباحثون أداتين هما اختبار التحصيل، ومقياس الاتجاه نحو التعليم الإلكتروني، أظهرت النتائج الأثر الإيجابي للاستخدام المنصية

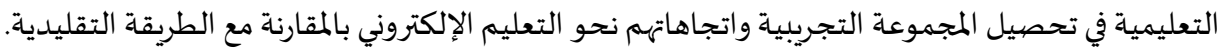
كما أجرى الزهر اني (2018) دراسـة التعرف على أثر استخدام منصية تعليمية في تنمية مهارات التواصل الرياضي ككل لدئل لدى طالبـات المرحلة

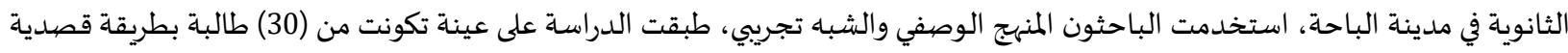

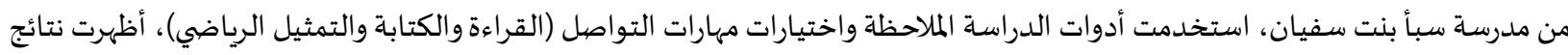

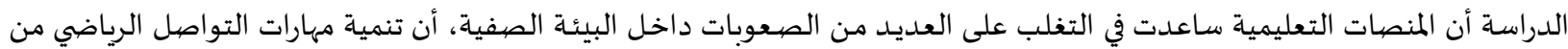

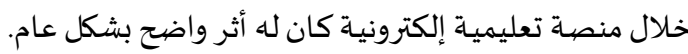

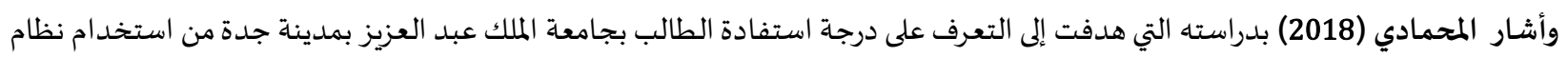
التعليم الإلكتروني (MES) والتحديات التي تواجه الطالب بجامعة الملك عبد العزيز بمدينة جدة من استخدام نظام التعليم الإلكتروني وتحسين

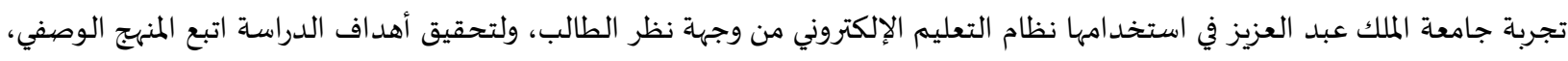

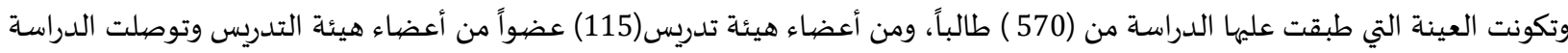
إلى أن المتوسط العام لدرجة استفادة الطالب من استخدام نظام التعليم الإلكتروني (EMES) جاء بدرجة متوسطة (86.3) بلغ المتوسط التهائة العام

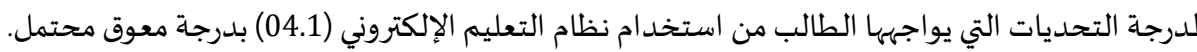
كما أجرى القضاة ومقابلة (2013) دراسة هدفت معرفة أبرز التحديات الخاصة بالتعليم الإلكتروني والتي تواجه أعضاء هيئة التدريس في

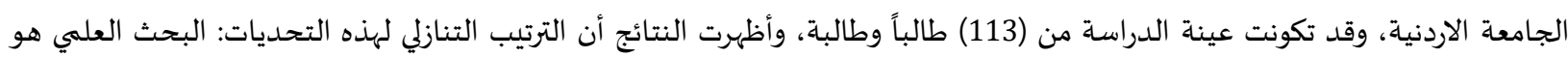
الأبرز، يليها تحديات تقنيات التعليم الإلكتروني والصعوبات المالية والإدارية والتقويم والتخطيط وصئه وصولاً إلى تصيميم التعليم الإلكتروني. وأجرت أناجرية (2011) دراسة هدفت إلى معرفة مستوى ممارسة المعلمات للتعليم المدمج وصعوباته التي تواجههن في تدريس مادة الكيمياء

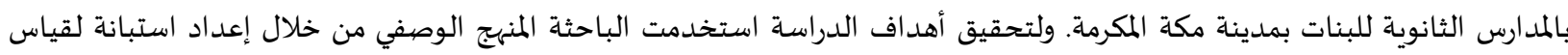

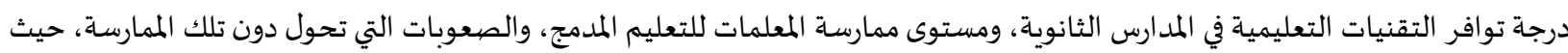

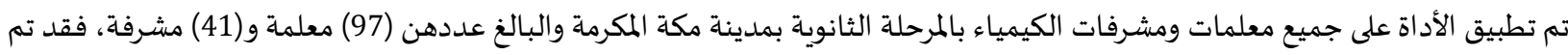

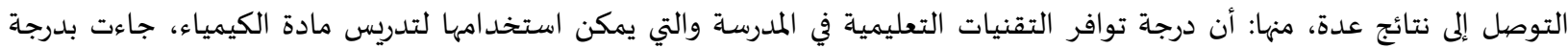

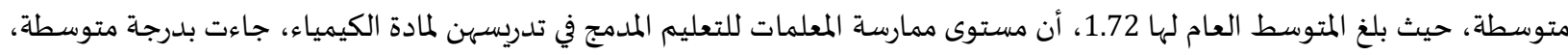

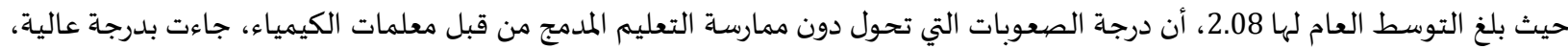

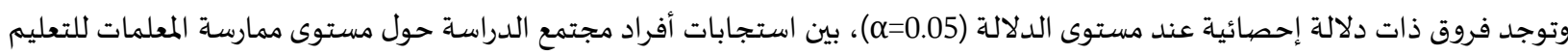

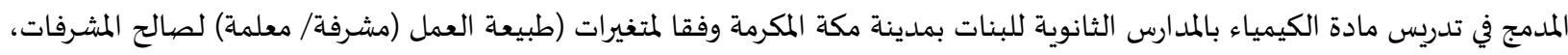

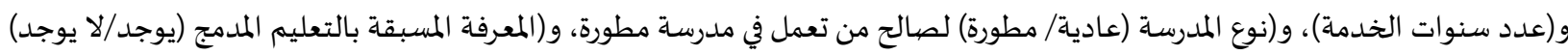

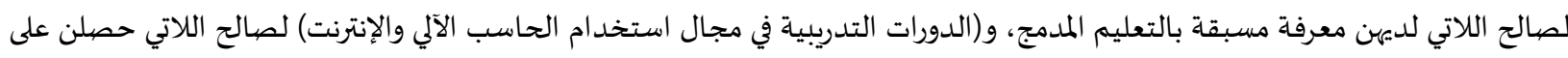


دورات تدربيةة، ولا توجد فروق ذات دلالة إحصائية عند مستوى الدلالة(

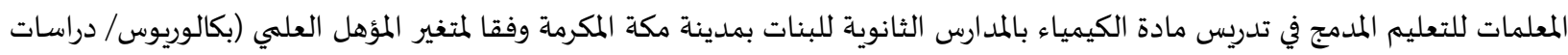
عليا)، وقد تم التوصل إلى عدد من التوصيات منها: ضرورة تعزيز وعي معلمات الكيمياء بالمرحلة الثانوية بمدينة مكاة المكرمة بأهمية ممارسة

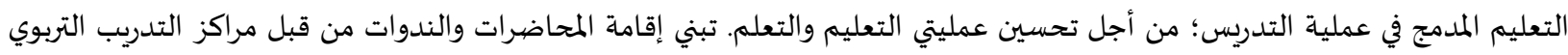
بإدارة التربية والتعليم لتعزيز فكرة استخدام تقنيات التعليم الإلكتروني لدى معلمات الكيمياء بالمرحلة الثانوية، وتقبل فكرة التغيير والانتقال

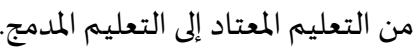

وتعقيباً على للدراسات السابقة يتبين أهها أظهرت نتائج إيجابية لاستخدام المعنصات المعات التعليمية ونجاح التعليم عن بعد واستمراره، كما أن المنصات

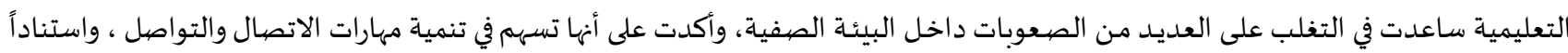

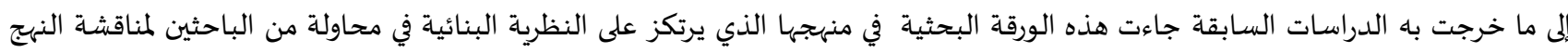

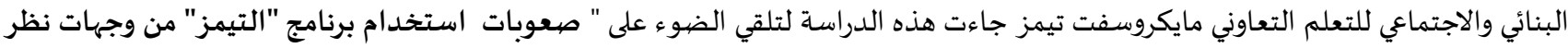

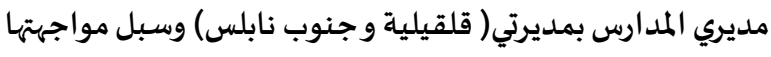

2.1. مشكلة الدراسة:

في ضوء الوضع الوبائي وفيروس كورونا (كوفيد 19) الذي انتشر في العالم بشكل عام، وفلسطين بشكل خاص، والذي كان له أكبر الأثر على العملية التعليمياة، وأدى إلى انقطاع الطلبة عن التوجه إلى مدارسهم وجامعاتهم بسبب انتشار هذا الوباء مما دفع بالقيادات التربوية في وزارة التربية

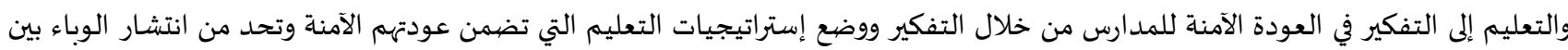

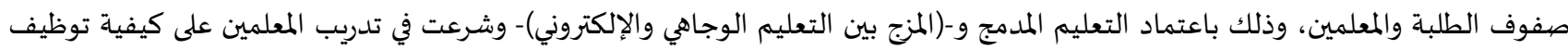
المنصات التعليمياة (Microsoft Teams) وتفعيلها كوسيلة لتوظيف التعليم عن بعد وضيمان استمرارية التعليم في حال إغلاق المدارس وتزايد المعائ انتشار

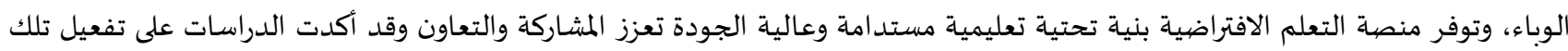
المنصات واستخدامها لزيادة تفاعل الطلبة و تحفيزهم على التعليم كدراسة ديباجيوتي (Debajyoti.2020) والتي هدفت إلى تقييم قابلية الاستخدام المتصور لـ Microsoft Teams كنظام أسـاسي للتعلم عبر الإنترنت خلال COVID-19 باستخدام مقياس قابلية استخدام النظام ونموذج قبول فئول التكنولوجيا في الهند، يتم استخدام Microsoft Teams كنظام أساسي مرجعي، كما أظهرت بعض الدرنس الدراسات السابقة تحديات التعليم الإلكتروني

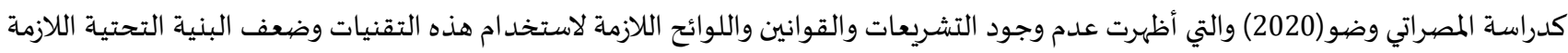
لذلك، ودراسة القضاة ومقابلة(2013) والتي كشفت عن تحديات التعليم الجامعي الإلكتروني، والتي تمثلت بتحديات تقنيات التعليم الإلكتروني

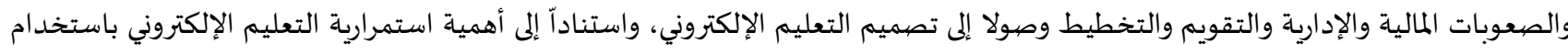

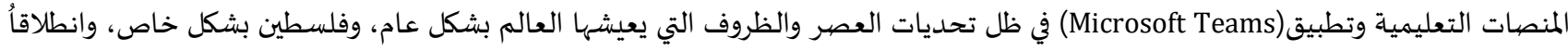

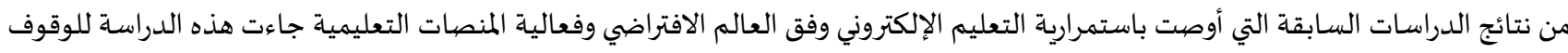

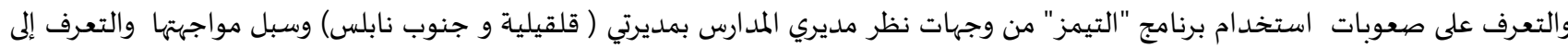
سبل مواجهة تلك الصعوبات.

3.1 3. أهداف الدراسـة:

سعت هذه الدراسة إلى تحقيق الأهد اف الآتية:

1. التعرف إلى " صعوبات استخدام برنامج "التيمز" من وجهات نظر مديري المدارس بمديرتي ( قلقيلية و جنوب نابلس) وسبل مواجهتها؟ 2. التعرف إلى " صعوبات استخدام برنامج "التيمز" من وجهات نظر مديري المدارس بمديرتي (قلقيلية و جنوب نابلس) تعزى لمتغيرات الدراسة (الجنس ، والمؤهل العلمي، وسنوات الخبرة، والمديرية) ؟ 3. التعرف إلى سبل مواجهة تلك الصعوبات لاستخدام برنامج " التيمز" من وجهات نظر مديري المدارس بمديرتي( قلقيلية و جنوب نابلس)؟

4.1 أسئلة الدراسة:

تتمحور الدراسة الحالية في الإجابة عن الأسئلة الآتية:

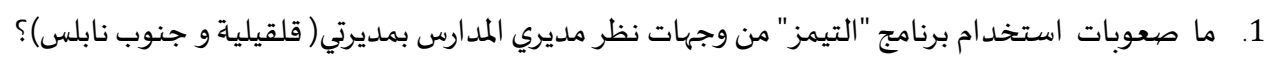
2. هل يوجد اختلاف في صعوبات استخدام برنامج "التيمز" من وجهات نظر مديري المدارس بمديرتي( قلقيلية و جنوب نابلس) باختلاف ماتس متغيرات

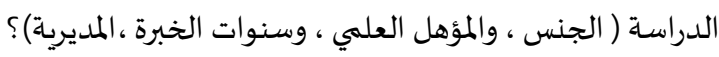
3. ما سبل مواجهة تلك " الصعوبات استخدام برنامج "التيمز" من وجهات نظر مديري المدارس بمديرتي( قلقيلية و جنوب نابلس)؟ 


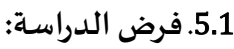

سعت الدراسـة الحالية إلى فحص الفرضية الصفيفرية الآتية:

لا توجد فروق ذات دلالة إحصائية عند مستوى الدلالة (م=0.05) بين متوسطات استجابات المديرين في صعوبات استخدام برنامج "التيمز" تعزى لمتغيرات الدراسـة: ( الجنس، والمؤهل العلمي ، وسنوات الخبرة، والمديرية) بمديرتي قلقيلية وجنوب نابلس.

6.1 - أهمية الدراسة:

تكتسب هذه الدراسة أهميتها البحثية فيما تقدمه للباحثين والتربويين من مادة علمية حول منصة (Microsoft Teams)، والوقوف على

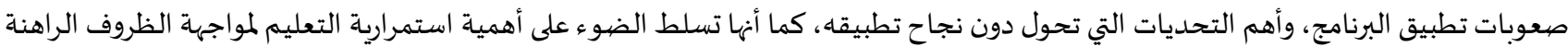

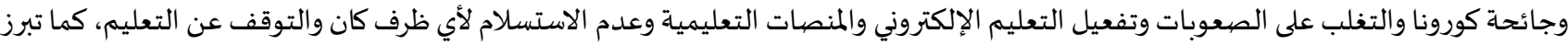

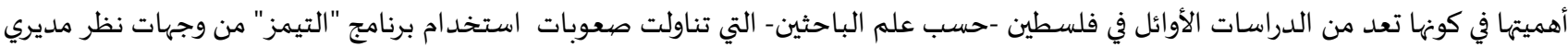
المدارس بمديرتي (قلقيلية و جنوب نابلس) وسبل مواجهتها وتكتسب هذه الدراسة أهميتها التطبيقية من خلال ما سترفعه من توصيات تفيد القائمين

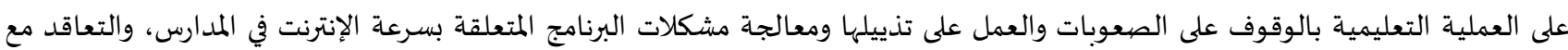
الشركات المزودة لتخفيض أسعار حزم الإنترنت للمعلمين والطلبة في سبيل تمكينهم من تطبيق البرنامج (Microsoft Teams)، وتحقيق أهداف المنهاج

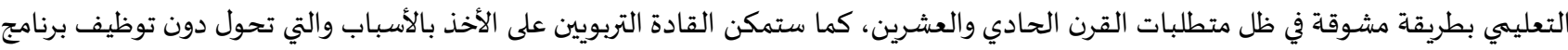
مايكروسفت تيمز، وحل المشكلات التي تواجاء المعلمين في توظيفه واستخدام البرامج التعليمية الإلكترونية الأخرى.

7.1 تحددت الدراسة الحالية بموضوعها المتمثل بصعوبات استخدام برنامج "التيمز" من وجهات نظر مديري المدارس بمديرتي (قلقيلية وجنوب

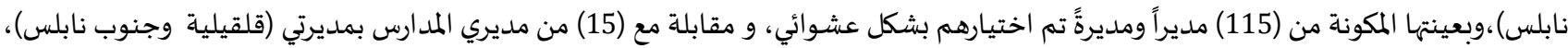

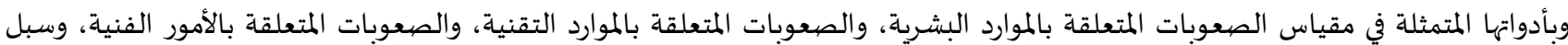
مواجهة تلك الصعوبات، وبالأساليب النوعية والإحصائية المستخدمة في تحليل نتائج الدراسة.

8.1

هبرنامج التيمز: وهو نظام جمع كل الأدوات التي تحتاجها في مكتبك في مكان واحد وفي مكان مهني متكامل وآمن، بما في ذلك الدردشة، والاتصالات

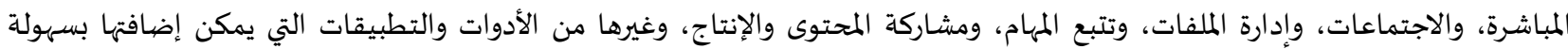

(سرحان، 2020)

ويعرفه الباحثون إجر ائياً: بأنه المنصة التعليمية الإلكترونية التي تم اعتمادها من قبل وزارة التربية والتعليم الفلسطينية لتفعيل التعليم الإلكتروني وإستراتيجية التعليم عن بعد والوقوف على صبعوبات تطبيق هذه البرنامج من خلال استجابات المبات المبحوثين على أداة الدراسة المتمثلة في الاستبانة في المدارس الحكومية الاساسية بمديرتي قلقيلية وجنوب نابلس. الصعوبات ويعرفها الباحثون إجر ائياً بأها: مجموعة من المعوقات أو المشكلات الفنية والمادية والإدارية التي تحول دون استخدام المعلم لبرنامج التيمز في العملية التعليمية. مديرية قلقيلية: إحدى مديريات التربية والتعليم الواقعة في شمال الضفة الغربية، والتي شملتها الدراسـة كحدود مكانية. مديرية جنوب نابلس: إحدى مديريات التربية والتعليم الواقعة في شمال الضفة الغربية، والتي شملتها الدراسة كحدود مكانية.

2. 2 الطريقة والإجراءات:

1.2. منهججية الدراسـة:

استخدمت الدراسة أسلوب الدمج بين المنهج الوصفي بصورتها التحليلية المتمثلة بجمع البيانات وتحليلها، والمنهج النوعي من خلال الاستماع إلى آراء المبحوثين، ووصفها، وحساب التكرارات، والنسب المئوية لها، وقد تناول موضيوع الدراسة" صعوبات استخدام برنامج "التيمز" من وجهات نظر

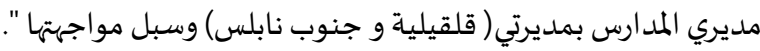
2.2 تكون مجتمع الدراسة من جميع مديري المدارس ، والبالغ عددهم (162) مديراً ومديرة في المدارس بمديرتي (قلقيلية و جنوب نابلس). 
3.2. تينة الدراسـة:

تكونت عينة الدراسة من (115) مديراً ومديرةً تم اختيارهم بشكل عشوائي، والجدول (1) يبين توزيع عينة الدراسة من مديري ومديرات المدارس

وفقاً لمتغيرات الدراسـة كما هو في الجدول (1) مندهاء

\begin{tabular}{|c|c|c|c|}
\hline النسبة المئوية \% & العدد & مستويات المتغير & المتغير \\
\hline 51.3 & 59 & ذكر & الجنس \\
\hline 48.7 & 56 & أنثى & \\
\hline 100.0 & 115 & المجموع & \\
\hline 72.2 & 83 & بكالوريوس & \\
\hline 27.8 & 32 & ماجستير فأعلى & \\
\hline 100.0 & 115 & المجموع & \\
\hline 7.0 & 8 & اقل من 5 سنوات & سنوات الخدمة \\
\hline 15.7 & 18 & من 5-10 سنوات & \\
\hline 77.4 & 89 & أكثر من 10 سنوات & \\
\hline 100.0 & 115 & المجموع & \\
\hline $\begin{array}{l}51.3 \\
\end{array}$ & 59 & جنوب نابلس & المديرية \\
\hline 48.7 & 56 & قلقيلية & \\
\hline 100.0 & 115 & المجموع & \\
\hline
\end{tabular}

كما تمّ إجراء مقابلة مع (15) من مديري المدارس بمديرتي (قلقيلية وجنوب نابلس) بهدف سبل مواجهة تلك الصعوبات التي تواجه المعلمين في

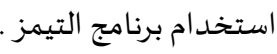
4.2 أداة الدراسـة:

استخدمت الدراسة الأداة والمقاييس الآتية:

أولاً: أداة الاستبانة لفحص صعوبات استخدام برنامج "التيمز" من وجهات نظر مديري المدارس بمديرتي (قلقيلية و جنوب نابلس).

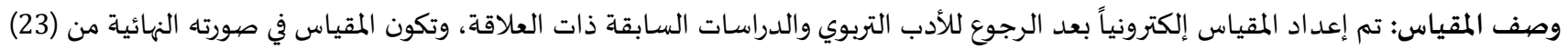

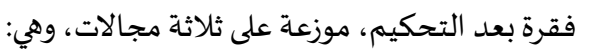
الصعوبات المتعلقة بالموارد البشرية: وتشتمل على الفقرات (10) (10). الصعوبات المتعلقة بالموارد التقنية:وتشتمل على الفقرات (11-11).

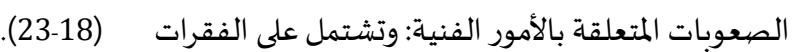
وقد تمَّ تصميم المقياس بناءً على مقياس ليكرت الخماسي والذي يبدأ بموافق بشدة (5) درجات، وموافق (4) درجات، ومحايد (3) درجات،

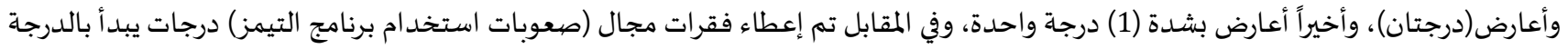

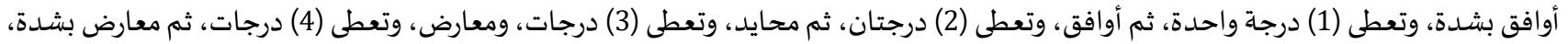
وتعطى (5) درجات، وذلك لاستبعاد تأثيرها العكسي على الدرجة الدهى الكلية.

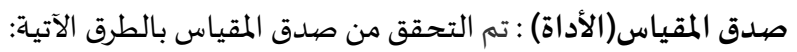
• صهدق المحكمين: تم عرض المقياس على (5) من أساتذة الجامعات من قسم المناهج والإدارة التربوية من كليات التربية في الجامعات الفلسطينية،

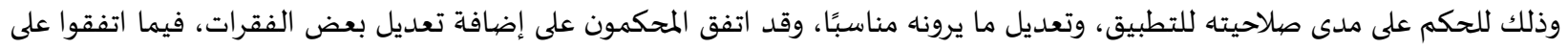
صلاحية باقي الفقرات للتطبيق، وبذلك أصبح المقياس بصورته النهائية مكوناً من (23) فقرة. الصيدق البنائي: تم تطبيق القائمة على عينة استطلاعية عددها (30) من المديرين من خارج عينة الدراسة، وتم إيجاد معاملات الارتباط بين الدرجة الكلية لكل مجال مع الدرجة الكلية لصعوبات استخدام برنامج التيمز، والجدول عينة (2) يوضنح ذلك. جدول(2): معاملات الارتباط بين الدرجة الكلية للمجال مع الدرجة الكلية لصعوبات استخدام برنامج التيمز

\begin{tabular}{|c|c|c|}
\hline قيمة الدلالة & معامل الارتباط & المجال \\
\hline 0.00 & $0.834^{* *}$ & الصعوبات المتعلقة بالموارد البشرية. \\
\hline 0.00 & $0.805^{* *}$ & الصعوبات المتعلقة بالموارد التقنية \\
\hline 0.00 & $0.855^{* *}$ & الصعوبات المتعلقة بالأمور الفنية \\
\hline
\end{tabular}


يتضح من الجدول (2) أن معاملات الارتباط مرتفعة ودالة، مما يؤكد على صبدق المقياس، وصلاحيته للتطبيق.

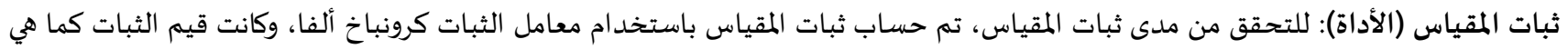
موضحة في الجدول (3).

\begin{tabular}{|c|c|c|}
\hline معامل الثبات & 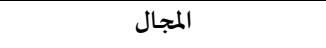 & رقم المجال \\
\hline 0.743 & الصعوبات المتعلقة بالموارد البشرية. & الأول \\
\hline 0.797 & الصعوبات المتعلقة بالموارد التقنية & الثاني \\
\hline 0.725 & الصعوبات المتعلقة بالأمور الفنية & 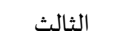 \\
\hline
\end{tabular}

معامل الثبات الكلي لمحور الاستبانة

يتضح من الجدول (3) أنَّ معاملات الثبات لمجالات المقياس لمحور صعوبات استخدام برنامج "التيمز" من وجهات نظر مديري المدارس بمديرتي

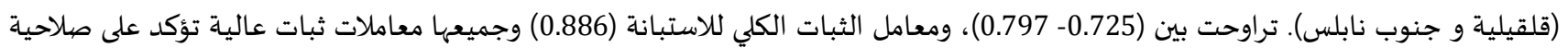

المقياس للتطبيق

ثانياً: المقابلة:

اعتمد الباحثون المقابلة شبه المنتظمة، وتكونت من سؤال مفتوح لتحقيق أهداف الدراسة وجمع المعلومات، وتدعم كل ما ورد في الاستبانة من

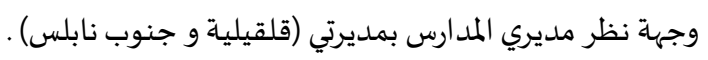
صددق المقياس: تم التحقق من الصدق الظاهري للمقياس من خلال عرض سؤال المقابلة على بعض محكمي الاستبانة من هيئة أعضاء التدريس في جامعة

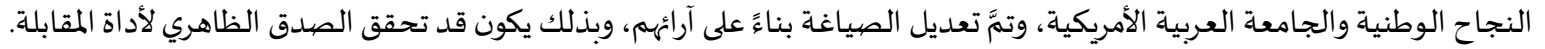

3. 1.3. إجابة السؤال الأول: ينص السؤال الأول على:" ما صعوبات استخدام برنامج "التيمز" من وجهات نظر مديري المدارس بمديرتي (قلقيلية وجنوب نابلس) ؟ (1) ولإجابة عن السؤال السابق ،تم استخراج المتوسطات الحسابية والانحرافات لصعوبات استخدام برنامج "التيمز" من وجهات نظر مديري

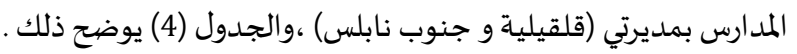

\begin{tabular}{|c|c|c|c|c|}
\hline ن=115 & الدرجة & الانحراف المعياري & المتوسط & المجال \\
\hline النسبة المئوية & & & الحسابي & \\
\hline \%82.4 & مرتفعة & 0.45 & 4.12 & الصعوبات المتعلقة بالموارد البشرية. \\
\hline$\% 81$ & مرتفعة & 0.60 & 4.05 & الصعوبات المتعلقة بالموارد التقنية \\
\hline \%76.8 & مرتفعة & 0.57 & 3.84 & الصعوبات المتعلقة بالأمور الفنية \\
\hline$\% 80$ & مرتفعة & 0.47 & 4.00 & الدرجة الكلية \\
\hline
\end{tabular}

يتضح من نتائج الجدول (4) أن صعوبات استخدام برنامج "التيمز" من وجهات نظر مديري المدارس بمديرتي( قلقيلية و جنوب نابلس) جاءت

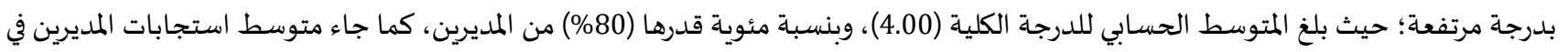
المجالات (الصعوبات المتعلقة بالموارد البشرية، والصعوبات المتعلقة بالموارد التقنية، والصعوبات المتعلقة بالأمور الفنية) مرتفعة، وهي نتائج حقيقية

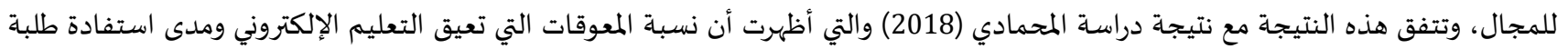

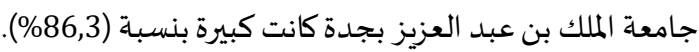
2.3. إجابة السؤال الثاني: والفرض الخاص به: والذي ينص على "لا توجد فروق ذات دلالة إحصائية عند مستوى الدلالة (م=0.05) بين متوسطات

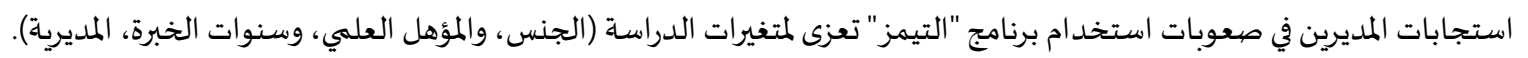

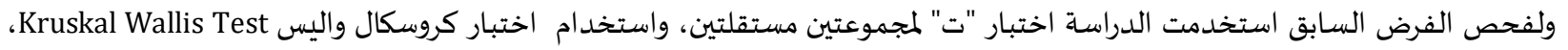
للكشف عن دلالة الفروق في صعوبات استخدام برنامج "التيمز" من وجهات نظر مديري المدارس بمديرتي (قلقيلية وجنوب نابلس في ضوء متغير سنوات الخبرة، وقد تم عرض نتائج كل متغير على حدة على النى النحو التالي: 
النتائج المتعلقة بمتغير الجنس:

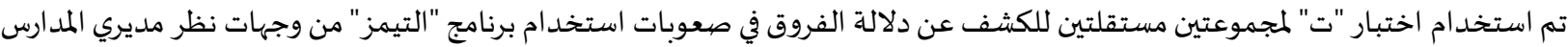

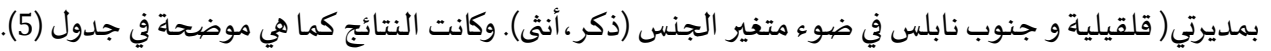

جدول (5): دلالة الفروق في صعوبات استخدام برنامج "التيمز" من وجهات نظر مديري المدارس بمديرتي( قلقيلية وجنوب نابلس في ضوء تبعاً لمتغير الجنس.

\begin{tabular}{|c|c|c|c|c|c|c|}
\hline \multirow[t]{2}{*}{ الدلالة الاحصبائية } & \multirow[t]{2}{*}{ قيمة (ت) } & \multicolumn{2}{|c|}{ أنثى (ن =56) } & \multicolumn{2}{|c|}{ ذكر(ن=59) } & \multirow[t]{2}{*}{ المجال } \\
\hline & & الانحراف & المتوسط & الانحراف & المتوسط & \\
\hline$* 0.02$ & 2.258 & 0.41 & 4.22 & 0.47 & 4.03 & الصعوبات المتعلقة بالموارد البشرية. \\
\hline$* 0.00$ & 4.318 & 0.49 & 4.28 & 0.62 & 3.83 & الصعوبات المتعلقة بالموارد التقنية \\
\hline$* 0.03$ & 2.174 & 0.56 & 3.96 & 0.57 & 3.73 & الصعوبات المتعلقة بالأمور الفنية \\
\hline$* 0.00$ & 3.461 & 0.42 & 4.15 & 0.47 & 3.86 & الدرجة الكلية \\
\hline
\end{tabular}

يتضح من نتائج جدول(5) وجود فروق دالة إحصائياً عند مستوى الدلالة (م=0.05) بين متوسطات استجابات المديرين نحو صعوبات استخدام

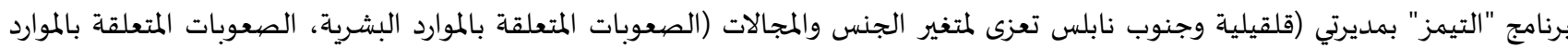

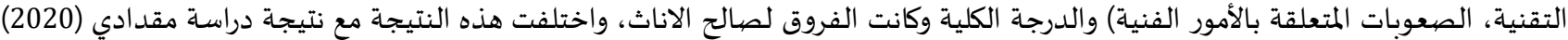

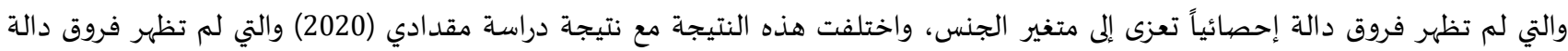
إحصائياً تعزى إلى متغير الجنس.

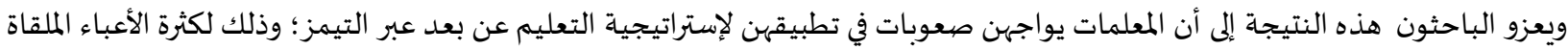

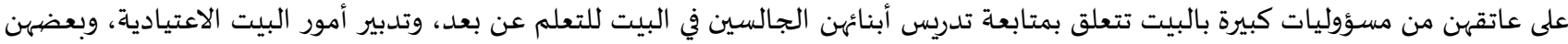

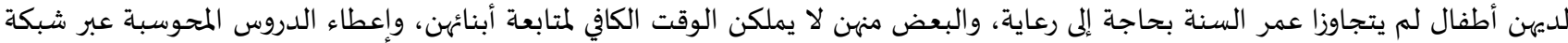

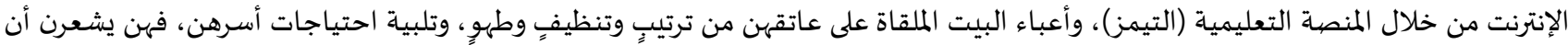

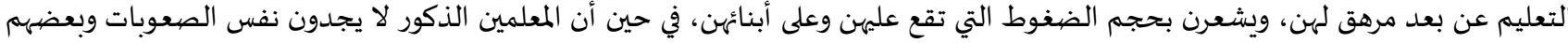
يتوجه إلى المدرسة لتنفيذ حصته عبر التيمز بسهولة.

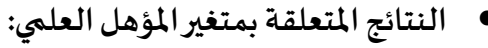

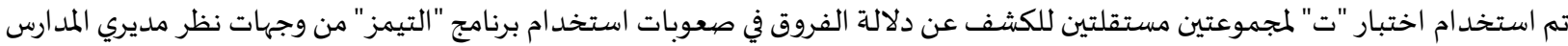

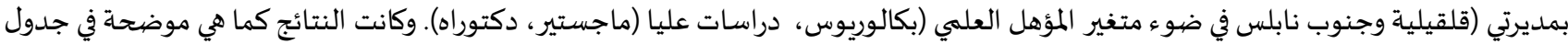

\begin{tabular}{|c|c|c|c|c|c|c|}
\hline \multirow[t]{2}{*}{ الدلالة الاحصائية } & \multirow[t]{2}{*}{ قيمة (ت) } & \multicolumn{2}{|c|}{ دراسات عليا (ن =32) } & \multicolumn{2}{|c|}{ بكالوريوس (ن=83) } & \multirow[t]{2}{*}{ المجال } \\
\hline & & الانحراف & المتوسط & الانحراف & المتوسط & \\
\hline 0.70 & 0.378 & 0.45 & 4.10 & 0.46 & 4.13 & الصعوبات المتعلقة بالموارد البشرية. \\
\hline 0.65 & 0.451 & 0.69 & 4.01 & 0.57 & 4.07 & الصعوبات المتعلقة بالموارد التقنية \\
\hline 0.83 & 0.210 & 0.54 & 3.82 & 0.58 & 3.85 & الصعوبات المتعلقة بالأمور الفنية \\
\hline 0.69 & 0.401 & 0.49 & 3.98 & 0.46 & 4.02 & الدرجة الكلية \\
\hline
\end{tabular}

يتضح من نتائج جدول(6) عدم وجود فروق ذات دلالة إحصائية عند مستوى الدلالة (م=0.05) بين متوسطات استجابات افراد العينة في جميع المجالات (الأول والثاني والثالث ) والدرجة الكلية تعزى لمتغير المؤهل العلمي ،واتفقت مع دراسة أناجربة (2011) في عدم وجود فروق دالة الدانة إحصائياتيبعا لمتغير المؤهل العلمي. ويعزو الباحثون هذه النتيجة أن المؤهل العلمي لا يؤثر في صعوبات تطبيق برنامج التيميز فهو برنامج جديد وقامت الوزارة بشرائه وتم اعتماده

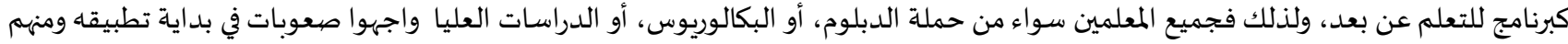

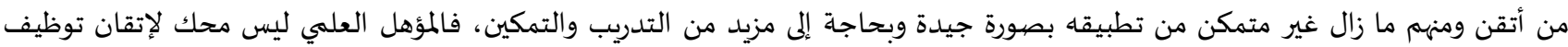

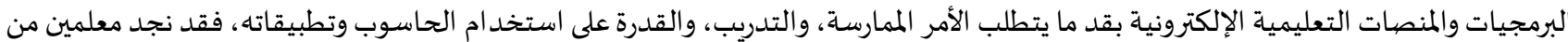
حملة الدبلوم متمكنين في هذا المجال، وقد نجد معلمين من حملة الماجستير ولا يملكون نفس المهارات والإمكانيات. 
النتائج المتعلقة بمتغير سنوات الخبرة:

تم استخدام اختبار كروسكال واليس Kruskal Wallis Test، للكشف عن دلالة الفروق في صعوبات استخدام برنامج "التيمز" من وجهات نظر

مديري المدارس بمديرتي( قلقيلية و جنوب نابلس في ضوء متغير سنوات الخبرة)، وكانت النتائج كما هي موضحة في في جدول (7)

\begin{tabular}{|c|c|c|c|c|}
\hline مستوى المعنوية & متوسط الرتب & 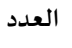 & سنوات الخبرة & المجالات \\
\hline \multirow[t]{4}{*}{0.32} & 40.94 & 8 & أقل من 5 سنوات & الصعوبات المتعلقة بالموارد \\
\hline & 59.28 & 18 & من5-10 سنوات & 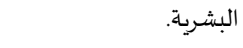 \\
\hline & 59.28 & 89 & أكثر من 10 سنوات & \\
\hline & & 115 & المجموع & \\
\hline \multirow[t]{4}{*}{0.90} & 60.13 & 8 & أقل من 5 سنوات & الصعوبات المتعلقة بالموارد \\
\hline & 60.75 & 18 & من5-10 سنوات & التقنية \\
\hline & 57.25 & 89 & أكثر من 10 سنوات & \\
\hline & & 115 & المجموع & \\
\hline \multirow[t]{4}{*}{0.22} & 42.56 & 8 & أقل من 5 سنوات & الصعوبات المتعلقة بالأمور \\
\hline & 51.50 & 18 & من5-10 سنوات & 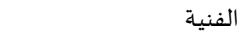 \\
\hline & 60.70 & 89 & أكثر من 10 سنوات & \\
\hline & & 115 & المجموع & \\
\hline \multirow[t]{4}{*}{0.59} & 46.56 & 8 & أقل من 5 سنوات & الدرجة الكلية \\
\hline & 58.03 & 18 & من من-10 سنوات & \\
\hline & 59.02 & 89 & أكثر من 10 سنوات & \\
\hline & & 115 & المجموع & \\
\hline
\end{tabular}

يتضح من الجدول (7) عدم وجود فروق ذات دلالة إحصائية عند مستوى الدلالة (م=0.05) بين صعوبات استخدام برنامج "التيمز" من وجهات

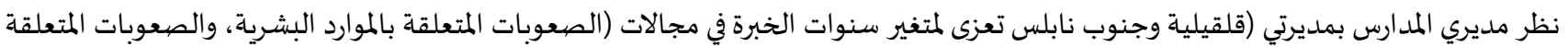
بالموارد التقنية، والصعوبات المتعلقة بالأمور الفنية، والدرجة الكلية)، واختلفت هده الدراسة، واختلفت هده الدراسة مع دراسة أناجرية (2011) في

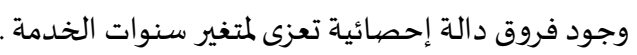

ويعزو الباحثون هذه النتيجة إلى أن توظيف التقنيات وبرامج الحاسوب، واستخدام برنامج التيمز يتطلب مهارات تكنولوجية، وقدرة على

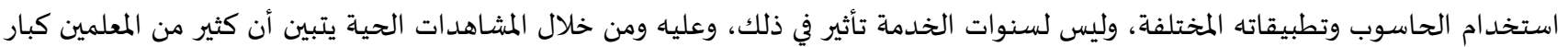
السن واجهوا صعوبات في توظيف إستراتيجية التعلم عن بعد عبر منصة التيمز، فهم لا يملكون مهارات القرن الحادي والعشرين وأهمها تكنولوجيا

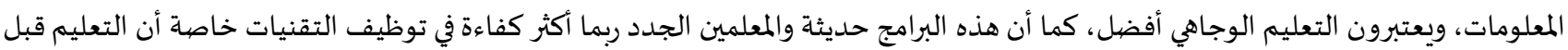
جائحة كورونا كان وجاهياً، ولذلك فسنوات الخبرة لا توثر في تطبيق برنامج التيمز أو صعوباته بقدر ما تؤثر الكفاءة، والمهارات، والممارسة. النتائج المتعلقة بمتغير المديرية: تم استخد ام اختبار "ت" لمجموعتين مستقلتين للكشف عن دئنس دلالة الفروق في صعوبات استخدام برنامج "التيمز" من وجهات نظر مديري المدارس بمديرتي (قلقيلية وجنوب نابلس في ضوء متغير المديرية (جنوب نابلس، قلقيلية)، وكانت النتائج كما هي موضحة في جدول (8)

الصyyynn

يتضح من نتائج جدول (8) عدم وجود فروق ذات دلالة إحصائية عند مستوى الدلالة (م=0.05) بين صعوبات استخدام برنامج "التيمز" من

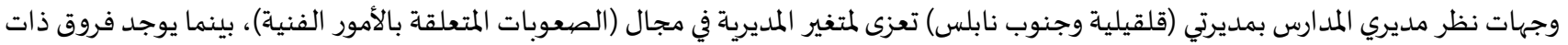

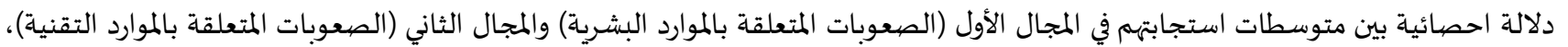
والدرجة الكلية لصالح مديرية جنوب نابلس. 
ويعزو الباحثون هذه النتيجة إلى أن استجابات مديري المدارس الحكومية بمديرية جنوب نابلس تبين أن عدد المستجيبين لا يؤثر في الصعوبات

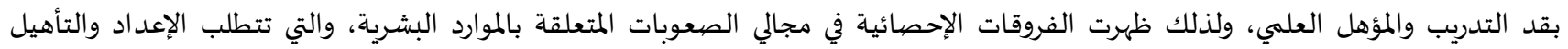
والتدريب، والصعوبات المتعلقة بالموارد التقنية، والتي تتطلب توفير أجهزة الحاسوب بين متناول المعلمين والطلبة، وتوفير شبكة إنترنت ذات سرعات الخهات

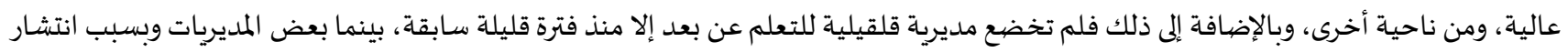

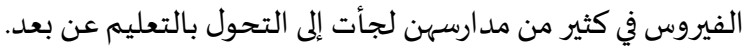

3.3. نتائج السؤال الثالث من الدراسـة، والذي ينص على: ما سبل مواجهة تلك " الصعوبات استخدام برنامج "التيمز" من وجهات نظر مديري المدارس بمديرتي( قلقيلية وجنوب نابلس) ؟ دان

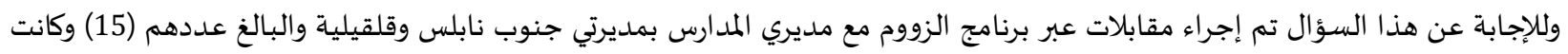
المقابلة شباه منتظمة وجاءت استجاباتهم على السؤال الثالث كما يلي:

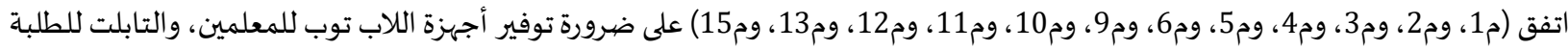

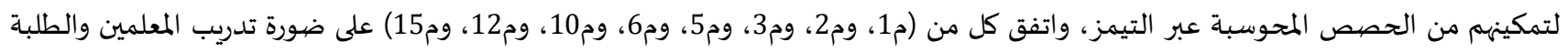

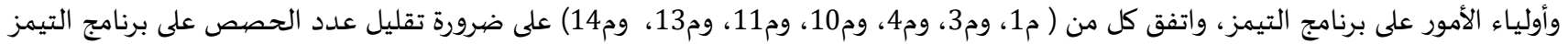

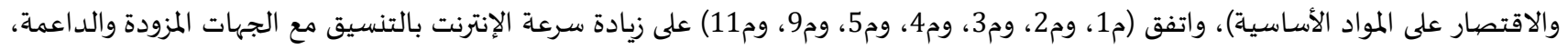

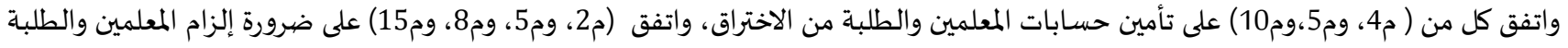

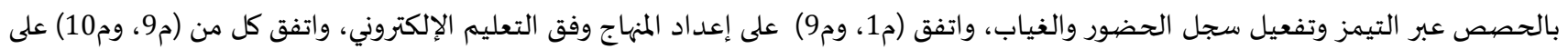
العودة على التعليم الوجاهي، واتفق (م10، وم12) على تخفيف عبء المتابعة والرقابة على المعلمين أثناء تفعيل الحصص عبر التيمز، وأشار(م14) على

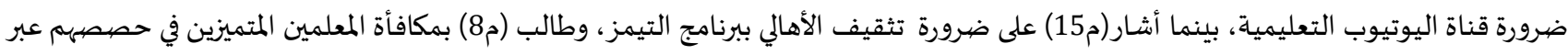
التيمز، والجدول (9) يبين التكرارات والنسب المئوية لاستجابات المديرين على السؤال الثالث. بلثمان.

جدول(9) التكرارات والنسب المئوية لاستجابات المديرين على السؤال الثالث

\begin{tabular}{|c|c|c|c|}
\hline 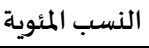 & 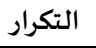 & 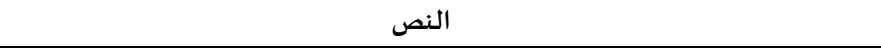 & 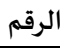 \\
\hline \multirow[t]{2}{*}{$\% 80$} & 12 & ضرورة توفير أجهزة اللاب توب للمعلمين، والتابلت للطلبة لتمكينهم من الحصص المحوسبة & 1 \\
\hline & & عبر التيمز. & \\
\hline$\% 53$ & 8 & ضرورة تدريب المعلمين والطلبة وأولياء الأمور على برنامج التيمز & 2 \\
\hline$\% 47$ & 7 & ضرورة تقليل عدد الحصص على برنامج التيمز والاقتصار على المواد الأساسي. & 3 \\
\hline$\% 47$ & 7 & زيادة سرعة الإنترنت بالتنسيق مع الجهات المزودة والداعمة & 4 \\
\hline$\% 27$ & 4 & ضرورة إلزام المعلمين والطلبة بالحصص عبر التيمز وتفعيل سجل الحضور والغياب & 5 \\
\hline$\% 20$ & 3 & تأمين حسابات المعلمين والطلبة من الاختراق & 6 \\
\hline$\% 13$ & 2 & إعداد المنهاج وفق التعليم الإلكتروني & 7 \\
\hline$\% 13$ & 2 & العودة على التعليم الوجاهي الي & 8 \\
\hline$\% 13$ & 2 & تخفيف عبء المتابعة والرقابة على المعلمين أثناء تفعيل الحصص عبر التيمز & 9 \\
\hline$\% 7$ & 1 & ضرورة قناة اليوتيوب التعليمية & 10 \\
\hline$\% 7$ & 1 & على ضرورة تثقيف الأهالي ببرنامج التيمز & 11 \\
\hline$\% 7$ & 1 & مكافأة المعلمين المتميزين في حصصهم عبر التيمز & 12 \\
\hline
\end{tabular}

يتضح من التكرارات والنسب المئوية في الجدول (9) أن أعلى التكرارات كانت(12) وبنسبة مئوية (80\%) وكانت مع ضرورة توفير أجهزة اللاب توب للمعلمين، والتابلت للطلبة لتمكينهم من الحصص المححوسبة عبر التيمز، يليها (8) تكرارات وبنسب مئوية (53\%) وكانت مع ضرورة تدريب المعلمين

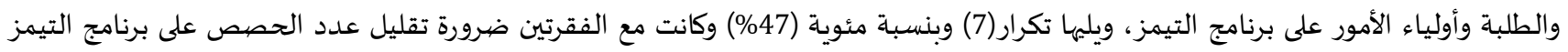

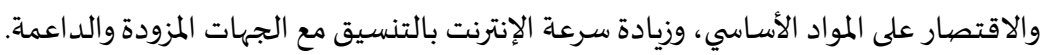

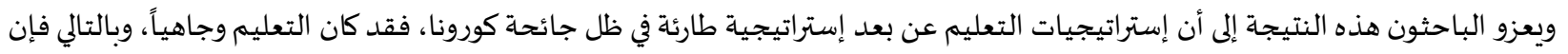

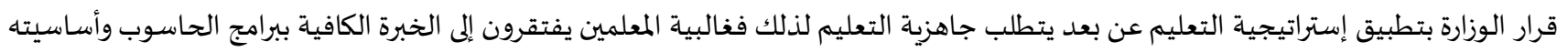

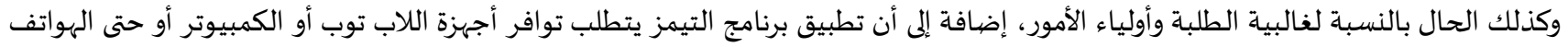

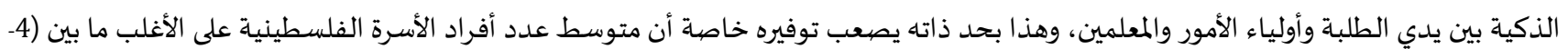
6) أطفال وهذا يعني أن الأسرة الواحدة تحتاج على الأقل توافر 3 أجهزة وبعض الأسر لا تملك المال لشراء جهاز واحد، ومن ناحية أخرى فتطبيق 
برنامج التيمز يحتاج إلى سرعة إنترنت عالية، ولكن بعض الأسر لا تقدر في ظل جائحة كورونا بسبب الأوضاع الاقتصادية من دفع تكاليف الإنترنت

خاصة أن البرنامج يحتاج إلى مساحة كبيرة وسرعة عالية مكلفة مادياً.

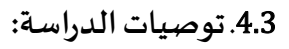

تعاقد الوزارة مع المؤسسات الداعمة لتوفير أجهزة الحاسوب للمعلمين والطلبة بأقل الأسعار والتكلفة.

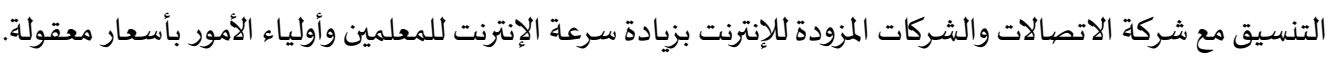
عقد الورش التدريبية للمعلمين والطلبة وأولياء الأمور على تطبيق برنامج التيمز. تفعيل القناة التعليمية عبر فضائية فلسطين واليوتيوب. إعداد مناهج تعليمية تتوافق مع متطلبات التعليم الإلكتروني. دمج التعليم الإلكتروني مع التعليم الوجاهي.

5 5.3. مقترحات الدراسة: • إجراء دراسات بحثية في مديريات مختلفة في فلسطين للوقوف على معوقات تطبيق برنامج التيمز.

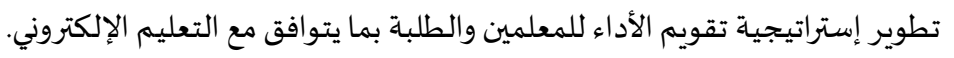
إعداد رزم إلكترونية للمنهاج لتوزيعها على الطلبة. تفعيل الإعلام التربوي حول دواعي تفعيل إستراتيجية التعليم عن بعد.

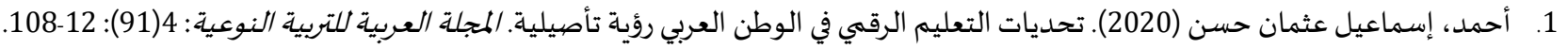

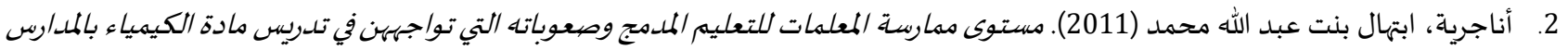

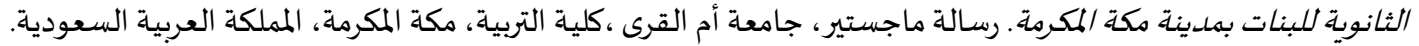

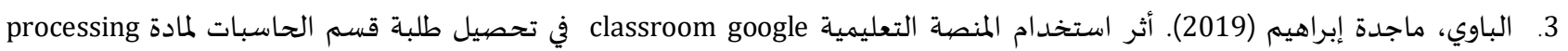

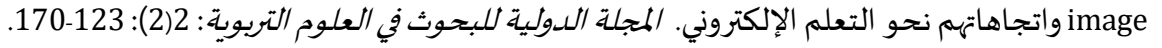

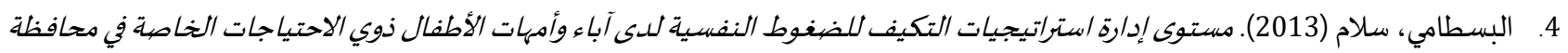
نابلس. رسالة ماجستير غير منشورة، جامعة النجاح الوطنية، نابلس، فلسطين.

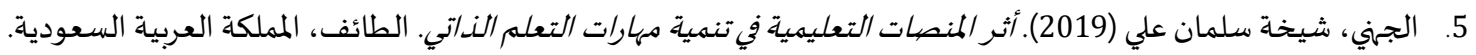
6.

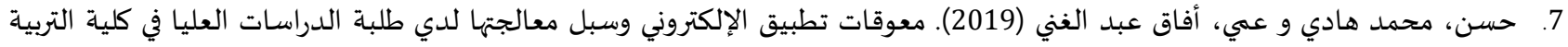

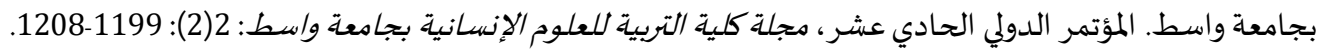

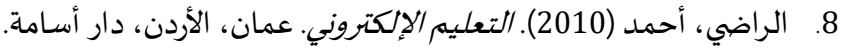

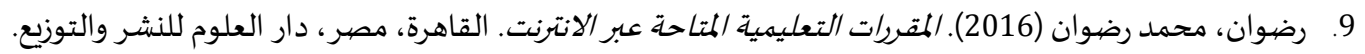

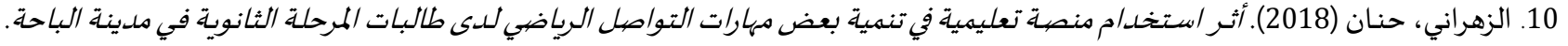
المجلة الدولية للعلوم التربوية والنفسية: 12(12): 223-255.

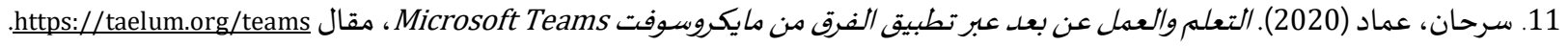

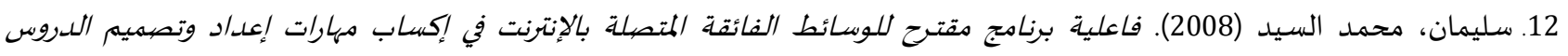

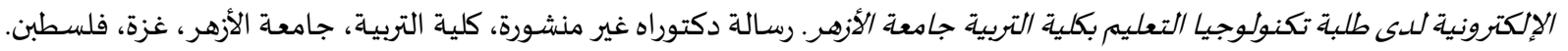

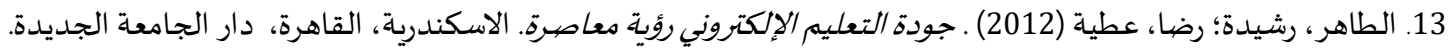

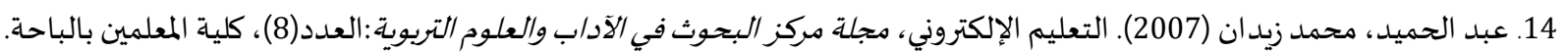

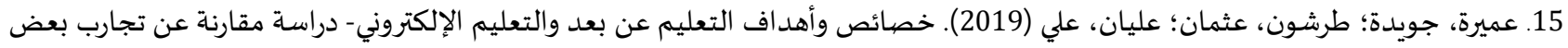
الدول العربية. المجلة العببية للآد/ب والدراسات الإنسانية: (6): 285-298. 
16. القضاة، خالد؛ مقابلة، بسام (2013). تحديات التعليم الإلكتروني التي تواجه أعضاء الهيئة التدريسية في الجامعات الأردنية الخاصة. مجلة المنارت: 19) 19 (3): 213 - 254

17. المحمادي، غدير .(2018). تقويم واقع استخدام نظام التعليم الإلكتروني (EMES) في برنامج التعليم عن بعد بجامعة الملك عبد العزيز من وجهة

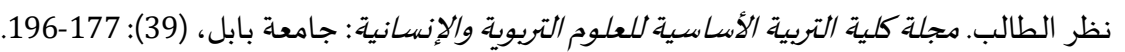

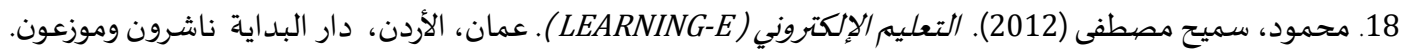

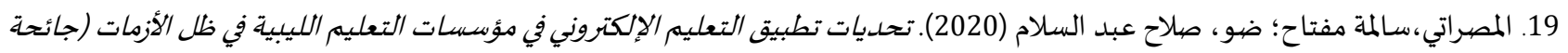

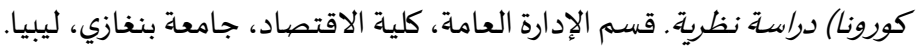

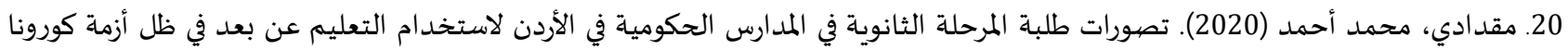

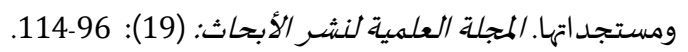
21. نشوان، تيسير؛ الزعانين، جمال (2003) .تقنيات التعليمروالتعلم. الطبعة الأولى، مكتبة الطالب الجامعي، غزة، فلسطين.

1. Allison, N., \& Hudson, J. (2020). Integrating and Sustaining Directed and Self-Directed Learning Through MS Teams and OneNote: Using Microsoft Teams and OneNote to Facilitate Communication, Assignments, and Portfolio Management. BALEAP TEL SIG Webinar, 03 Jun.

2. Basilaia, Giorgi; Kvavadze, David (2020). Transition to Online Education in Schools during a SARS-CoV-2 Coronavirus (COVID-19) Pandemic in Georgia. Journal Pedagogical Research, 5(4). https://doi.org/10.29333/pr/7937

3. Debajyoti. Vajirasak Vanijja (2020). Perceived usability evaluation of Microsoft Teams as an online learning platform during COVID-19 using system usability scale and technology acceptance model in India. Children and Youth Services Review, Volume 119. https://doi.org/10.1016/j.childyouth.2020.105535

4. Liu, Chenxi; Xu, Fan (2020). Evaluating Videoconferencing Systems for the Quality of the Educational Experience, Correia, Ana-Paula. Distance Education, 41(4): 429-452. https://doi.org/10.1080/01587919.2020.1821607

5. Rojabi, Ahmad Ridho (2020). Exploring EFL Students' Perception of Online Learning via Microsoft Teams: University Level in Indonesia. English Language Teaching Educational Journal, 3(2): 163-173. https://doi.org/10.12928/eltej.v3i2.2349

6. Tsai, P. (2018). Business Chat Apps in 2018: Top Players and Adoption Plans. The Spiceworks Community. [Online]. https://community.spiceworks.com/blog/3157-business-chat-apps-in-2018-topplayers-andadoption-plans\%0A

ثالثاً: المو اقع الإلكترونية:

1. https://www.arrajol.com/content/140571 
المجلة الدولية للدراسـات التربوية والنفسية

International Journal of Educational \& Psychological Studies (EPS)

Journal Homepage: https://www.refaad.com/views/EPSR/Home.aspx

\title{
The difficulties of using Teams program from the views of school principals in Qalqilya and South Nablus and ways to confront them
}

\author{
Abeer Khaled Hussein Qashu' 1, Suha Asaad Ibrahim Jallad 2, Shadi Khaled Hussein Qashu' 3 \\ 1,2 An-Najah National University, Palestine \\ ${ }^{3}$ Arab American University, Palestine \\ 1 abeer.qashoo7@gmail.com, 2 Sohajallad8@gmail.com, ${ }^{3}$ shadiqashoo@gmail.com
}

Received : 18/4/2021 Revised : 8/5/2021 Accepted : 25/5/2021 DOI : https://doi.org/10.31559/EPS2021.10.2.4

Abstract: The study aimed to know the difficulties of using Teams program from the views of school principals in Qalqilya and South Nablus administrators, The study was used to merge between the analytical descriptive approach and the qualitative approach, The study community may be from all (162) school principals and director from Qalqilya and South Nablus, The indiscriminate sample (115) director, the results showed that the difficulties of using the Teams program from the views of school principals in Qalqilya and Southern Nablus came high and an average of (4.00) and statistical differences at the level of significance $(\alpha=0.05)$ Among the averages of managers responses to the difficulties of using the Thames program in Qalqilya and south of Nablus are attributed to gender, female benefit, and lack of differences for vengeance years' experience, scientific and managers in the field of technical matters, while there are differences in the first field (difficulties in the first field) Human resources and second domain (technical resource difficulties) and the overall degree, and the Directorate of South Nablus, and ways to confront these difficulties were the most important provision of laptops B for teachers, and tablets for students to enable them to comply with computerized quotas , and recommended the Ministry contracting with supporting institutions to provide computer organs of teachers and students, holding training workshops and suggested research studies in various directorates in Palestine.

Keywords: teams Program; Difficulties; Directorate of South Nablus; Qalqiliya Directorate.

\section{References:}

1. 'bd Alhmyd, Mhmd Zydan (2007). Alt'lym Alelktrwny, Mjlh Mrkz Albhwth Fy Aladab Wal'lwm Altrbwyh: Al'dd(8), Klyt Alm'lmyn Balbahh.

2. 'myrh, Jwydh: Trshwn, 'thman: 'lyan, 'ly (2019). Khsa's Wahdaf Alt'lym 'n B'd Walt'lym Alelktrwny- Drash Mqarnh 'n Tjarb B'd Aldwl Al'rbyh. Almjlh Al'rbyh Lladab Waldrasat Alensanyh: (6): 285-298.

3. Ahmd, Esma'yl 'thman Hsn (2020). Thdyat Alt'lym Alrqmy Fy Alwtn Al'rby R'yh Tasylyh. Almjlh Al'rbyh Lltrbyh Alnw'yh: 4(91): 12-108.

4. Anajryh, Abthal Bnt 'bd Allh Mhmd (2011). Mstwa Mmarsh Alm'lmat Llt'lym Almdmj Ws'wbath Alty Twajhhn Fy Tdrys Madh Alkymya' Balmdars Althanwyh Llbnat Bmdynh Mkh Almkrmh. Rsalt Majstyr, Jam't Am Alqra ,Klyt Altrbyh, Mkh Almkrmh, Almmlkh Al'rbyh Als'wdyh.

5. Albawy, Majdh Ebrahym (2019). Athr Astkhdam Almnsh Alt'lymyh Classroom Google Fy Thsyl Tlbh Qsm Alhasbat Lmadt Processing Image Watjahathm Nhw Alt'Im Alelktrwny. Almjlh Aldwlyh Llbhwth Fy Al'lwm Altrbwyh: 2(2): 123-170.

6. Albstamy, Slam (2013). Mstwa Edart Astratyjyat Altkyf Lldghwt Alnfsyh Lda Aba' Wamhat Alatfal Dwy Alahtyajat Alkhash Fy Mhafzt Nabls. Rsalt Majstyr Ghyr Mnshwrh, Jam't Alnjah Alwtnyh, Nabls, Flstyn.

7. Alhjaya, Mhmd Na'l (2010). Waq' Alt'lym Alelktrwny Fy Aljam'at Alardnyh. Almjlh Aldwlyh Altrbwyh Almtkhssh: 2(2): 122.

8. Hsn, Mhmd Hady W 'my, Afaq 'bd Alghny (2019). M'wqat Ttbyq Alelktrwny Wsbl M'aljtha Ldy Tlbh Aldrasat Al'lya Fy Klyt Altrbyh Bjam'eh Wast. Alm'tmr Aldwly Alhady 'shr, Mjlt Klyt Altrbyh Ll'lwm Alensanyh Bjam't Wast: 2(2): 1199-1208. 
9. Aljhny, Shykhh Slman 'ly (2019). Athr Almnsat Alt'lymyh Fy Tnmyh Mharat Alt'lm Aldaty. Alta'f, Almmlkh Al'rbyh Als'wdyh.

10. Almhmady, Ghdyr.(2018). Tqwym Waq' Astkhdam Nzam Alt'lym Alelktrwny (Emes) Fy Brnamj Alt'lym 'n B'd Bjam't Almlk 'bd Al'zyz Mn Wjht Nzr Altalb. Mjlt Klyt Altrbyh Alasasyh Ll'elwm Altrbwyh Walensanyh: Jam't Babl, (39): 177-196.

11. Mhmwd, Smyh Mstfa (2012). Alt'lym Alelktrwny (Learning-E ). 'man, Alardn, Dar Albdayh Nashrwn Wmwz'wn.

12. Mqdady, Mhmd Ahmd (2020). Tswrat Tlbh Almrhlh Althanwyh Fy Almdars Alhkwmyh Fy Alardn Lastkhdam Alt'lym 'n B'd Fy Zl Azmt Kwrwna Wmstjdatha. Almjlh Al'lmyh Lnshr Alabhath: (19): 96-114.

13. Almsraty,Salmh Mftah: Dw, Slah 'bd Alslam (2020). Thdyat Ttbyq Alt'lym Alelktrwny Fy M'essat Alt'lym Allybyh Fy Zl Alazmat (Ja'ht Kwrwna) Drash Nzryh. Qsm Aledarh Al'amh, Klyt Alaqtsad, Jam'tBnghazy, Lybya.

14. Nshwan, Tysyr: Alz'anyn, Jmal (2003). Tqnyat Alt'lym Walt'lm. Altb'h Alawla, Mktbt Altalb Aljam'y, Ghzh, Flstyn.

15. Alqdah, Khald: Mqablh, Bsam (2013). Thdyat Alt'lym Alelktrwny Alty Twajh A'da' Alhy'h Altdrysyh Fy Aljam'at Alardnyh Alkhash. Mjlt Almnarh: 19(3): 213- 254.

16. Alrady, Ahmd (2010). Alt'lym Alelktrwny. 'man, Alardn, Dar Asamh.

17. Rdwan, Mhmd Rdwan (2016). Almqrrat Alt'lymyh Almtahh 'br Alantrnt. Alqahrh, Msr, Dar Al'lwm Llnshr Waltwzy'.

18. Slyman, Mhmd Alsyd (2008). Fa'lyt Brnamj Mqtrh Llwsa't Alfa'qh Almtslh Balentrnt Fy Eksab Mharat E'dad Wtsmym Aldrws Alelktrwnyh Lda Tlbh Tknwlwjya Alt'lym Bklyh Altrbyh Jam't Alazhr. Rsalt Dktwrah Ghyr Mnshwrh, Klyt Altrbyh, Jam't Alazhr, Ghzh, Flstbn.

19. Srhan, 'mad (2020). Alt'lm Wal'ml 'n B'd 'br Ttbyq Alfrq Mn Maykrwswft Microsoft Teams, Mqal https://taelum.org/teams.

20. Altahr, Rshydh: Rda, 'tyh (2012). Jwdh Alt'lym Alelktrwny R'yh M'asrh. Alaskndryh, Alqahrh, Dar Aljam'h Aljdydh.

21. Alzhrany, Hnan (2018). Athr Astkhdam Mnsh T'lymyh Fy Tnmyh B'd Mharat Altwasl Alryady Lda Talbat Almrhlh Althanwyh Fy Mdynt Albahh. Almjlh Aldwlyh Ll'lwm Altrbwyh Walnfsyh: 12(1): 223-255. 


\section{ملحق(1): الاستبانة بصوقها النهائية}

حضرة مدير(ة) مدرسة تحية طيبة وبعد:

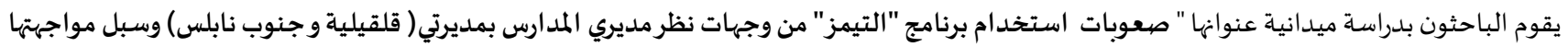

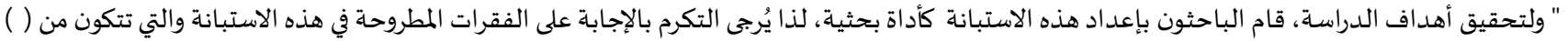

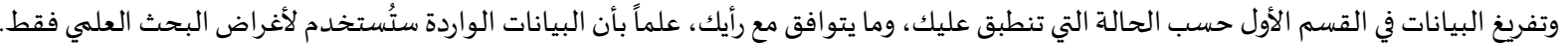
شاكرين لكم حُسن تعاونكم

القسم الأول:

أولاً: البيانات الشخصية

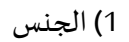

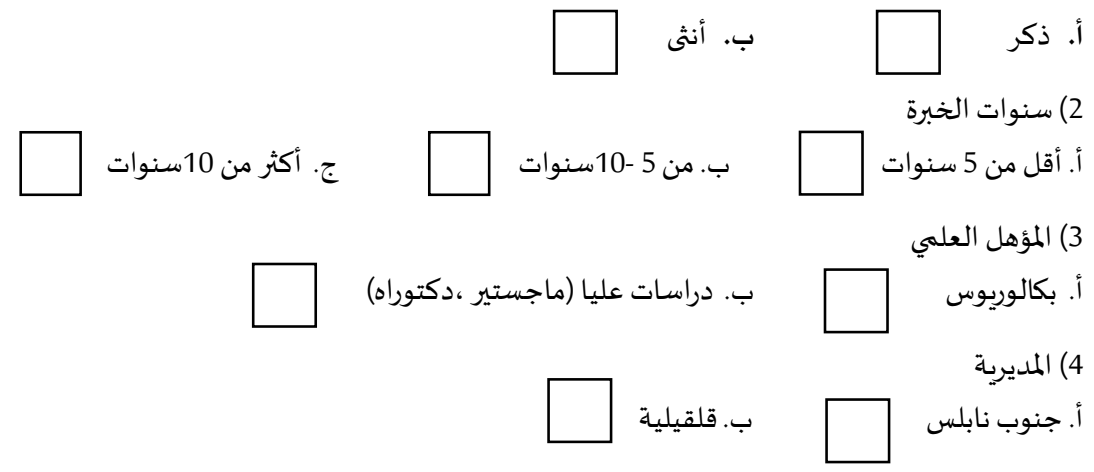

القسم الثاني: برنامج التيمز) (Microsoft Teams)

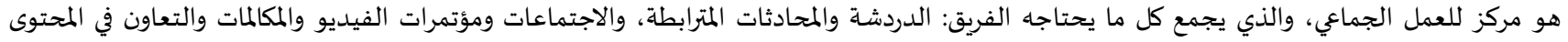

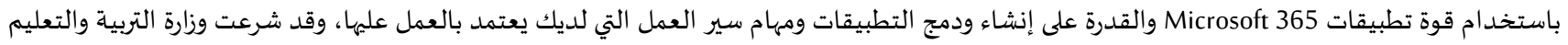

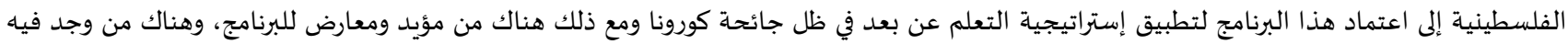
الصعوبات المتعددة وعليه جاءت هذه الاستبانة للكشف عن هذه الصعوبات.

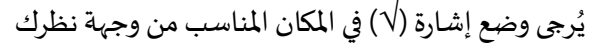

\begin{tabular}{|c|c|c|c|c|c|c|}
\hline معارض بشدة & 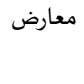 & محايد & 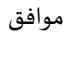 & مشدة & 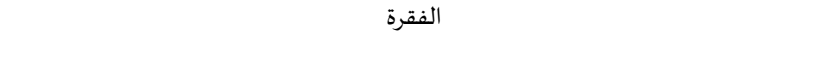 & 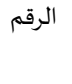 \\
\hline \multicolumn{7}{|c|}{ المجال الأول: الصعوبات المتعلقة بالموارد البشرية } \\
\hline & & & & & عدم قناعة المعلمين بفائدة التعليم الإلكتروني وتوظيف برنامج التيمز. & 1. \\
\hline & & & & & افتقار بعض المملمين إلى الخبرة الكافية في استخدام الحاسوب وتطبيقاته المختلفة. & 2. \\
\hline & & & & & تدربب المعلمين في كيفية توظيف برنامج التيمز غير كاف. & 3. \\
\hline & & & & & يفضل بعض المعلمين التعليم الوجاهي على التعلم عن بعد. & 4. \\
\hline & & & & & يحتاج الطلبة وأولياء الأمور التدربب على كيفية استخدام برنامج التيمز. & 5. \\
\hline & & & & & تذمر المعلمين من الأعباء الكتابية ونصاب الحصص إلى جانب توظيف برنامج التيمز. & 6. \\
\hline & & & & & غياب المشاركة والتفاعل عن قرب في برنامج التيمز. & 7. \\
\hline & & & & & تذمر الأهالي بسبب عدم كفاية أجهزة الحاسوب لأفراد الأسرة . & 8. \\
\hline & & & & & افتقار الطلبة لمهارات استخدام برنامج التيمز. & 9. \\
\hline & & & & & كثافة حصص التيمز في اليوم الواحد. & 10. \\
\hline \multicolumn{7}{|c|}{ المجال الثاني: الصعوبات المتعلقة بالموارد التقنية } \\
\hline & & & & & تفتقر العديد من المدارس للبنية التحتية لشبكات الإنترنت. & 11. \\
\hline & & & & & قلة عدد أجهزة الحاسوب المتاحة للمعلمين. & 12. \\
\hline & & & & & قلة عدد أجهزة الحاسوب المتاحة للطلبة. & 13. \\
\hline & & & & & تكرار انقطاع التيار الكهربائي المفاجئ. & 14. \\
\hline & & & & & 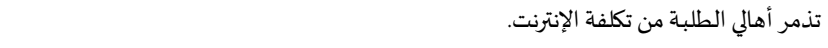 & 15. \\
\hline & & & & & ضعف شبكة الانترنت يؤدي إلى تعليق البرنامج. & 16. \\
\hline & & & & & تحميل الفيديو أو البور بوينت أو فتح اللوحة البيضاء تحتاج إلى إنترنت عالي السرعة مما يؤدي & 17. \\
\hline
\end{tabular}




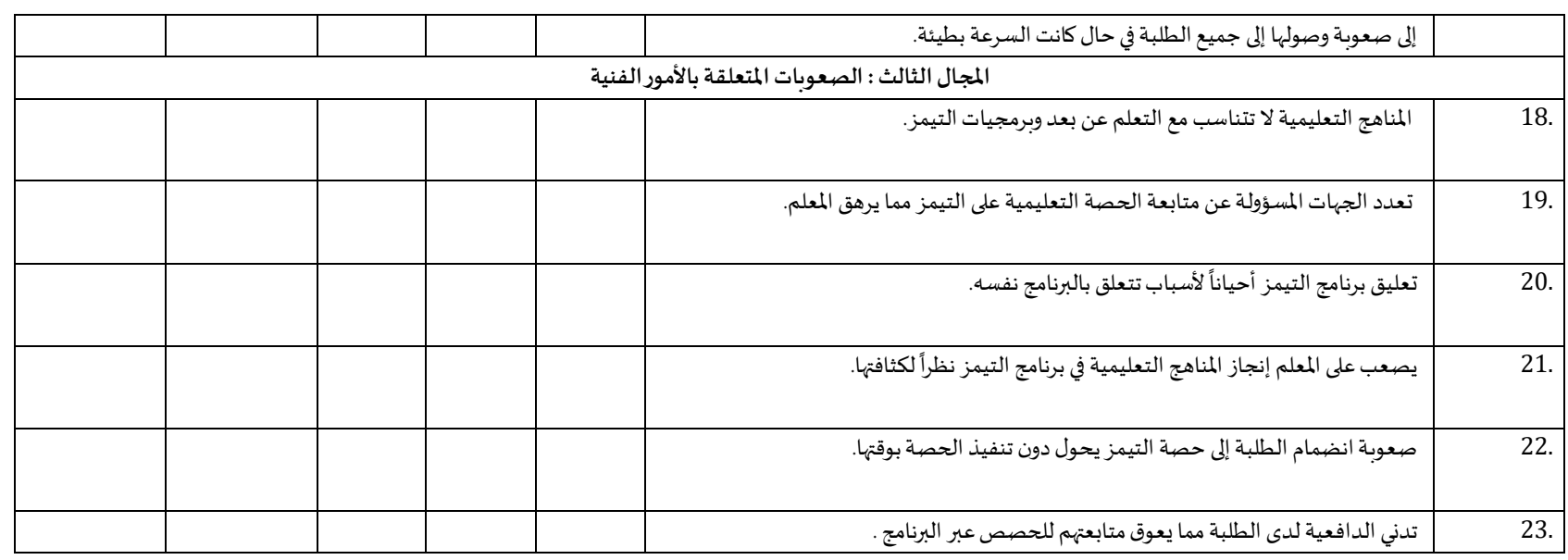

شكراً على حسن تعاونكم 